\title{
CX3CR1 Deficiency Alters Microglial Activation and Reduces Beta-Amyloid Deposition in Two Alzheimer's Disease Mouse Models
}

\author{
Sungho Lee, ${ }^{, \dagger}$ Nicholas H. Varvel, ${ }^{\star \dagger}$ \\ Megan E. Konerth, ${ }^{*}$ Guixiang $\mathrm{Xu},{ }^{*}$ \\ Astrid E. Cardona, ${ }^{*}$ Richard M. Ransohoff, ${ }^{*}$ \\ and Bruce T. Lamb* ${ }^{\star \dagger \ddagger}$ \\ From the Department of Neurosciences, Lerner Research \\ Institute,* The Cleveland Clinic, Cleveland; and the Departments \\ of Neurosciences, ${ }^{\dagger}$ and Genetics, ${ }^{\ddagger}$ Case Western Reserve University \\ School of Medicine, Cleveland, Obio
}

Microglia, the primary immune effector cells in the brain, continually monitor the tissue parenchyma for pathological alterations and become activated in Alzheimer's disease. Loss of signaling between neurons and microglia via deletion of the microglial receptor, CX3CR1, worsens phenotypes in various models of neurodegenerative diseases. In contrast, CX3CR1 deficiency ameliorates pathology in murine stroke models. To examine the role of CX3CR1 in Alzheimer's disease-related $\beta$-amyloid pathology, we generated APPPS1 and R1.40 transgenic mouse models of Alzheimer's disease deficient for CX3CR1. Surprisingly, CX3CR1 deficiency resulted in a gene dose-dependent reduction in $\beta$-amyloid deposition in both the APPPS1 and R1.40 mouse models of AD. Immunohistochemical analysis revealed reduced staining for $\mathrm{CD} 68$, a marker of microglial activation. Furthermore, quantitative immunohistochemical analysis revealed reduced numbers of microglia surrounding $\beta$-amyloid deposits in the CX3CR1-deficient APPPS1 animals. The reduced $\beta$-amyloid pathology correlated with reduced levels of TNF $\alpha$ and CCL2 mRNAs, but elevated IL1 $\beta$ mRNA levels, suggesting an altered neuroinflammatory milieu. Finally, to account for these seemingly disparate results, both in vitro and in vivo studies provided evidence that $C X 3 C L 1 / C X 3 C R 1$ signaling alters the phagocytic capacity of microglia, including the uptake of $A \beta$ fibrils. Taken together, these results demonstrate that loss of neuron-microglial fractalkine signaling leads to reduced $\beta$-amyloid deposition in mouse models of $\mathrm{AD}$ that is potentially mediated by altered activation and phagocytic capability of CX3CR1- deficient microglia. (Am J Pathol 2010, 177:2549-2562; DOI: 10.2353/ajpath.2010.100265)

Alzheimer's disease (AD) is a progressive neurodegenerative disorder characterized by extracellular deposits of $\beta$-amyloid $(A \beta)$ peptides in senile plaques. Accumulating evidence suggests that neuroinflammatory processes may contribute to the pathophysiology of $A D$. Microglia, the resident inflammatory cells of the brain, are found in a highly activated state in the AD brain, including morphological alterations, proliferation, increased expression of cell surface receptors, and secretion of inflammatory cytokines and chemokines. ${ }^{1,2}$ However, recent in vivo imaging studies demonstrated that activated microglia migrate to newly formed $A \beta$ deposits in mouse models of $A D$ and may restrict their growth by removing $A \beta$ fibrils. ${ }^{3-5}$ Therefore, depending on the local conditions, microglia may exhibit beneficial or detrimental activation programs. ${ }^{6}$ Indeed, various genetically modified mouse models have convincingly demonstrated the role for various inflammatory pathways in altering microglial activation and $A \beta$ deposition, including chemokines/cytokines, ${ }^{7-9}$ cyclooxygenase, ${ }^{10}$ and complement. ${ }^{11}$ While these studies suggest a correlative link between neuroin-

Supported by a grant from the American Health Assistance Foundation (07-997, to B.T.L.), National Institutes of Health grant AG023012 (B.T.L.), an investigator-initiated research grant from the Alzheimer's Association (B.T.L.), a grant from the Charles A. Dana Foundation (R.M.R.), a Career Transition Award from the National Multiple Sclerosis Society (TA-3021, to A.E.C.), National Research Service Award Fellowship F30NS068003 (S.L.), and an anonymous foundation.

Accepted for publication June 29, 2010.

Supplemental material for this article can be found on http://ajp. amjpathol.org.

Current address of N.H.V.: Department of Cellular Neurology, HertieInstitute for Clinical Brain Research, University of Tübingen, Tübingen, Germany; of A.E.C.: Department of Biology and STCEID, University of Texas San Antonio, San Antonio, Texas.

Address reprint requests to Bruce T. Lamb, Ph.D., Lerner Research Institute, The Cleveland Clinic, Department of Neurosciences, 9500 Euclid Avenue, NC30, Cleveland, OH 44195-0001. E-mail: lambb@ccf.org. 
flammation and $\mathrm{AD}$ pathophysiology, the molecular mechanisms underlying beneficial or deleterious microglial activities remain incompletely understood.

The chemokine fractalkine (CX3CL1) and its cognate receptor, CX3CR1, play an important role in neuroinflammation via paracrine signaling between neurons and microglia. ${ }^{12-14}$ While CX3CR1 is expressed by many leukocyte cell types in the periphery, ${ }^{15}$ in the brain CX3CR 1 is exclusively expressed by microglia ${ }^{13}$ whereas CX3CL 1 is highly expressed within neurons. ${ }^{14} \mathrm{CX} 3 \mathrm{CL} 1$ can signal to CX3CR1 in a membrane bound form, or as a secreted ligand after constitutive or inducible cleavage by the ADAM10 and ADAM17 metalloproteases, respectively. ${ }^{16}$ Genetic variants in CX3CR1, which result in defective CX3CL1-CX3CR1 interactions, have been associated with age-related macular degeneration, a neuroinflammatory disorder. ${ }^{17,18}$ Finally, disruption of CX3CL1-CX3CR1 signaling promotes neurodegeneration in mouse models of Parkinson's disease, amyotrophic lateral sclerosis, as well as in neuroinflammation induced by systemic administration of lipopolysaccharide. ${ }^{13}$ Conversely, lack of CX3CR1 is protective in murine stroke models. ${ }^{19,20}$

To examine the role of CX3CR1 signaling in amyloid pathology associated with $A D$, we mated $C \times 3 c r 1$ knockout mice to two different mouse models of $A D$ that exhibit either rapid deposition of primarily $A \beta 42$ (the APPPS1 model) ${ }^{21}$ or gradual deposition of primarily $A \beta 40$ (the R1.40 model). ${ }^{22-24}$ Surprisingly, CX3CR1 deficiency resulted in a gene dose-dependent reduction in $A \beta$ deposition as well as the numbers of microglia surrounding the $A \beta$ deposits in both mouse models of AD. CX3CR1deficient mice with amyloid pathology exhibited altered microglial activation with reduced immunohistochemical staining for the microglial activation marker CD68 and altered expression of cytokines and chemokines. Finally, we demonstrate that CX3CL1-CX3CR1 signaling reduces microglial phagocytic capabilities and that blocking CX3CL1-CX3CR1 signaling increases uptake of $A \beta$, suggesting that CX3CR1 deficiency leads to enhanced $A \beta$ clearance.

\section{Materials and Methods}

\section{Mice}

The APPPS1-21 (APPPS1) mouse line coexpresses human amyloid precursor protein harboring the K670M/ N671L familial AD mutation and presenilin 1 harboring the L166P familial $A D$ mutation, under the control of the neuron-specific Thy1 promoter. ${ }^{21}$ APPPS1 mice (in an isogenic C57BL/6J background; kindly provided by Mathias Jucker) were mated to $C \times 3 \mathrm{Cr}^{-1-}$ animals ${ }^{15}$; congenic on the C57BL/6J background) and subsequently intercrossed to generate APPPS1; $\mathrm{C} \times 3 \mathrm{Cr}^{+/-}$and APPPS1;CX3 $\mathrm{Cr}^{-1-}$ genotypes on a defined C57BL/6J genetic background. Aged-matched APPPS $1 ; \mathrm{C} \times 3 \mathrm{Cr} 1^{+/+}$ animals were used as controls.

The R1.40 transgene is a full genomic copy of human APP (carried on a 650-kb yeast artificial chromosome clone) carrying the K670M/N671L familial AD mutation associated with early-onset familial AD. Creation of the R1.40 transgenic mouse strain and subsequent backcrossing to inbred strains has been described previously. $22,23,25$ Homozygous R1.40 animals, maintained on the C57BL/6J genetic background, were mated to $\mathrm{C} \times 3 \mathrm{Cr}^{-1-}$ animals (also maintained on the C57BL/6J genetic background) and subsequently intercrossed to generate animals homozygous for the R1.40 transgene and either homozygous or heterozygous for the Cx3cr 1 knockout allele and controls. Animals were housed at the Cleveland Clinic Biological Resources Unit, a facility fully accredited by the Association of Assessment and Accreditation of Laboratory Animal Care. All procedures were approved by the Institutional Animal Care and Use Committee of the Cleveland Clinic.

\section{Western Blot Analysis}

Mice were sacrificed by cervical dislocation, and their brains were removed, sagittally bisected, and snap frozen. Tissues were subsequently homogenized in $10 \mathrm{vol}$ umes of Tris-buffered saline (50 mmol/L Tris; $\mathrm{pH}$ 7.4, 150 $\mathrm{mmol} / \mathrm{L} \mathrm{NaCl}, 1 \mathrm{mmol} / \mathrm{L}$ EDTA, $0.1 \%$ Triton-X100) or 20 volumes of T-PER reagent (Thermo Scientific, Rockford, IL) with a protease inhibitor cocktail (Sigma-Aldrich, St. Louis, MO). Total brain homogenates were subsequently sonicated to shear the DNA and centrifuged to remove nuclei and cellular debris. Total protein concentration was determined using the Pierce BCA Protein Assay Kit (Thermo Scientific). Brain protein (25-30 $\mu \mathrm{g}$ ) was run on a Novex NuPage, 4 to $12 \%$ Bis-Tris gel (Invitrogen) and transferred to a PVDF membrane. The resulting Western blots were blocked with $5 \%$ milk and subsequently incubated with CT15 antibody (rabbit polyclonal; 1:5000, kindly provided by Edward $\mathrm{H}$. Koo) raised against the C terminus of $\mathrm{APP}^{26}$ or $6 \mathrm{E} 10$ antibody (mouse monoclonal; 1:2000; Signet Labs) raised against amino acids 1-16 of human $A \beta$.

After overnight incubation at $4^{\circ} \mathrm{C}$ with primary antibodies, blots were washed with PBS and detected using anti-mouse or anti-rabbit secondary antibodies conjugated to horseradish peroxidase (1:20,000; Jackson ImmunoResearch Laboratories, West Grove, PA) diluted in $5 \%$ milk with $0.1 \%$ Tween 20 . To confirm equal protein loading, anti- $\alpha$-tubulin antibody (mouse monoclonal; 1:5000; Neomarkers, Fremont, CA) or anti-glyceraldehyde 3-phosphate dehydrogenase (GAPDH; mouse monoclonal; 1:20,000; Millipore, Billerica, MA) was used. For quantification, blots were incubated with secondary antibody mixtures (goat anti-mouse IRDye 700 and goat anti-rabbit IRDye 800; 1:20,000; Rockland Immunochemicals, Gilbertsville, PA) for one hour at RT. Infrared signals were measured and quantified in an Odyssey infrared imaging system (Li-Cor Biosciences, Lincoln, $\mathrm{NE})$. The integrated intensity ratio for APP/ $\alpha$-tubulin or C-terminal fragment (CTF) $\beta / \alpha$-tubulin was calculated, and the mean \pm SEM for eight independent experiments were used for statistical analysis. 


\section{$A \beta E L I S A$}

For determination of $A \beta 42$ levels, a commercially available ELISA kit was used (Invitrogen). Mouse hemi-brains were extracted with $5 \mathrm{~mol} / \mathrm{L}$ guanidine $\mathrm{HCl}$ and incubated at room temperature for four hours. Homogenates were centrifuged to remove insoluble debris, supernatants were diluted 1:5000 in standard diluent buffer, and ELISA was carried out according to manufacture instructions. The plate was read using a microtiter plate reader. Optical density values were fitted against the standard curve and $\mathrm{pmol} / \mathrm{g}$ wet brain calculated. The results were tabulated as mean \pm SEM and compared using an unpaired t-test.

\section{Histology}

Mice were deeply anesthetized with Avertin and transcardially perfused with ice-cold $0.1 \mathrm{~mol} / \mathrm{L}$ sodium phosphate buffer, followed by $4 \%$ paraformaldehyde in PBS as described previously. ${ }^{27}$ The brain was dissected, immediately removed from the cranium, and transferred to fresh $4 \%$ paraformaldehyde in PBS at $4^{\circ} \mathrm{C}$ overnight. The brains were subsequently cryoprotected by sinking in $30 \%$ sucrose/PBS at $4^{\circ} \mathrm{C}$ overnight. After bisecting across the midline, the brains were embedded in Optimal Cutting Temperature (OCT) Compound and 30 $\mu \mathrm{m}$ free-floating cryostat sections cut and stored in PBS at $4^{\circ} \mathrm{C}$ until use.

\section{Thioflavine S Staining}

Sections were pretreated in $10 \mathrm{mmol} / \mathrm{L}$ sodium citrate buffer ( $\mathrm{pH} 6.0,0.05 \%$ Triton-X100) for 15 minutes at $95^{\circ} \mathrm{C}$ to quench eGFP expression in CX3CR1-deficient animals, which reduced background fluorescence to that observed in non-transgenic controls (modified from Ref. 28; data not shown). Sections were mounted onto SuperPlus glass slides and air-dried and immersed in 1\% Thioflavine $\mathrm{S}$ (in $\mathrm{dH}_{2} \mathrm{O}$ ) for five minutes. Sections were subsequently hydrated in $70 \%$ ethanol and washed twice in PBS. The slides were coverslipped with 1:1 PBS:glycerol, and edges were sealed with nail polish.

Low-power images of cortex and hippocampus were compiled to form a series of overlapping images that were used to obtain an integrated image using Photoshop. The number of Thioflavine S-positive plaques in the cortex (below the pial surface and above the corpus callosum) and the hippocampus (excluding the subiculum and the fimbriae) was quantified. For all experiments, four separate sections, $360 \mu \mathrm{m}$ apart, were quantified from each mouse, and all sections were taken from the same brain regions. All data were expressed as mean density or total count of Thioflavine S-positive plaques \pm SEM and statistically significant alterations between the threes genotypes determined by one-way analysis of variance followed by Newman-Keuls post hoc test (GraphPad Prism, La Jolla, CA).

\section{Immunohistochemistry}

For diaminobenzidine immunohistochemistry, sections were first rinsed in PBS containing $0.1 \%$ Triton-X100 (PBST), pretreated with $10 \mathrm{mmol} / \mathrm{L}$ sodium citrate buffer $\left(\mathrm{pH} 6.0,0.05 \%\right.$ Triton-X100) for 15 minutes at $95^{\circ} \mathrm{C}$ for epitope retrieval. Sections were subsequently cooled for 30 minutes at room temperature, immersed in 0.3\% hydrogen peroxide in PBS for 30 minutes to remove endogenous peroxidase activity, and blocked in 5\% normal goat serum in PBS containing $0.3 \%$ Triton $\mathrm{X}-100$ for one hour at room temperature. After incubation overnight at $4^{\circ} \mathrm{C}$ in blocking buffer containing either rat monoclonal anti-CD45 (diluted 1:500; Serotec, Oxford, UK), rat monoclonal anti-CD68 (diluted 1:500; Serotec, Oxford, UK), mouse monoclonal anti-human $A \beta$ (clone 6E10; diluted 1:500; Signet Labs), rabbit polyclonal anti-glial fibrillary acidic protein (GFAP; diluted 1:500; Sigma-Aldrich), mouse monoclonal anti-phosphorylated tau (clone AT8; diluted 1:500; Thermo Scientific), or anti-APP (clone CT15; diluted 1:500) antibodies, slides were washed three times in PBST and incubated for one hour at room temperature in blocking buffer containing biotintylated anti-rat, anti-mouse, or anti-rabbit IgG antibody (diluted 1:200; Vector, Burlingame, CA). After three additional PBST washes, sections were incubated in Vectastain ABC Elite reagent (Vector) for one hour at room temperature and developed using diaminobenzidine with nickel chloride enhancement, according to the manufacturer's instructions. Sections stained for CD45 or CD68 were additionally counterstained with Congo Red to visualize dense core $A \beta$ deposits. Finally, free-floating sections were mounted onto SuperPlus glass slides and coverslipped with Permount.

For double fluorescent immunohistochemistry, sections were rinsed in PBST, pretreated with sodium citrate buffer to quench microglial eGFP, cooled for 30 minutes at room temperature, blocked for one hour at room temperature, and incubated overnight at $4^{\circ} \mathrm{C}$ in blocking buffer containing anti-lba1 rabbit polyclonal antibody (diluted 1:1000; Wako, Richmond, VA) and the anti-A $\beta$ mouse monoclonal antibody 4G8 (diluted 1:500; Signet Labs). After three PBST washes, sections were incubated for one hour at room temperature in blocking buffer containing secondary antibodies conjugated to fluorescent Alexa dyes (diluted 1:1000; Invitrogen). The sections were finally washed three times in PBST, incubated with TO-PRO-3 (diluted 1:1000 in PBS; Invitrogen) for 10 minutes at room temperature, mounted onto SuperPlus glass slides, and coverslipped with hard-set Vectashield mounting media (Vector). Controls included sections in which the fluorescent dyes were swapped as well as no primary antibody (data not shown).

\section{Quantification of Microglia}

Twenty- to thirty- $\mu \mathrm{m}$ thick Z-stacks were collected at $\times 40$ magnification with $1 \mu \mathrm{m}$ between each slice using a Leica SP5 confocal microscope, and images were post- 
processed using ImageJ. To minimize any potential experimental bias, high-resolution confocal Z-stacks that spanned the entire thickness of the section were obtained and quantified via an unambiguous parameter (ie, number of cells rather than percent area or optical density). In addition, all sections were immunostained and imaged together using the same parameters. To determine the number of microglia surrounding each $A \beta$ deposit, Iba1-positive cells whose nuclei or primary processes directly overlapped 4G8 immunoreactivity in a given plane of focus were counted. Only those microglia whose nuclei were present in the Z-stack were included in the analysis. The size of the $A \beta$ deposits were calculated from arbitrarily thresholded maximum projections of 4G8 immunoreactivity and subsequently used to determine the number of microglia surrounding $A \beta$ deposits of different sizes. Three random fields within the cortex were analyzed from three independent nonadjacent sections per mouse, with four animals analyzed per genotype. Data from 35 plaques of each size category were included for statistical analyses using one-way analysis of variance followed by NewmanKeuls post hoc test (GraphPad Prism) and presented as mean \pm SEM.

\section{RNA Extraction and Reverse Transcription-PCR}

Hemi-brains of APPPS $1 ; C \times 3 \mathrm{Cr}^{+/+}$, APPPS1;C $\times 3 \mathrm{Cr} 1^{+/-}$, APPPS1;Cx3 $\mathrm{Cr}^{-1-}$, and nontransgenic C57BL/6J animals were snap frozen and stored at $-80^{\circ} \mathrm{C}$ until RNA extractions were performed. RNA was extracted using the Tri Reagent as described by the manufacturer (Invitrogen). Total RNA (50 ng/uL) was converted to cDNA using the High Capacity cDNA Reverse Transcription kit (Applied Biosystems Inc. [ABI], Foster City, CA) and amplified using specific TaqMan probes on the $A B I$ 7300 Real-Time PCR System. TaqMan probes used in the current studies include: chemokine (C-C motif) ligand 2 (CCL2; Mm00441241_ml), CX3CL1 (Mm01243036

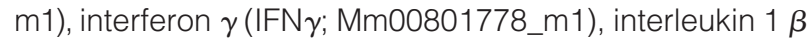
(IL1 $\beta ;$ Mm00434228_ml), IL4 (Mm00445259_m1), IL10 (Mm00439615_g1), IL6 (Mm00446191_m1), and tumor necrosis factor $\alpha$ (TNF $\alpha$; Mm00443258_m1). The relative amount of each transcript was determined via normalization across all samples to the endogenous control, GAPDH (part \#4308313) as recommended by ABI. In addition, before initiation of the studies, cDNA was serially diluted and amplified using the respective TaqMan probes to ensure that the amount of cDNA used was in the linear range. RNA samples from each individual animal were run in triplicate.

To quantify the relative expression levels of the different transcripts for each genotype, we calculated the difference $(\Delta \mathrm{Ct})$ between the cycle threshold of the genes of interest (GOI) and the housekeeping gene Gapdh. From this data, the $-\Delta \Delta \mathrm{Ct}\left(-\left[\Delta \mathrm{Ct}_{\mathrm{GOI}}-\Delta \mathrm{Ct}_{\mathrm{B} 6}\right]\right)$ was computed and converted to a value relative to the entire brain using the formula $2^{-\Delta \Delta C t}$. The results were tabulated as mean \pm SEM and compared between genotypes via one-way analysis of variance followed by Newman-Keuls post hoc test.

\section{Cell Culture}

Primary microglia were cultured from postnatal day 0-3 $\mathrm{C} \times 3 \mathrm{Cr}^{+1+}$ and $\mathrm{C} \times 3 \mathrm{Cr}^{-1-}$ mice as described previously. ${ }^{29}$ Briefly, dissected cerebral cortices were sequentially rinsed with PBS containing $1 \mathrm{~g} / \mathrm{L}$ glucose, minced, and digested with $0.05 \%$ trypsin-EDTA for 20 minutes at $37^{\circ} \mathrm{C}$. Cells were triturated in DMEM/F12 containing $20 \%$ heat-inactivated fetal bovine serum (HI-FBS) and 1\% penicillin-streptomycin and plated in cell culture flasks. Media was changed the next day to DMEM/F12 with $10 \%$ HI-FBS.

After 14 days of incubation, microglia were isolated as described previously ${ }^{30}$ by removal of astrocytes by incubation in $0.25 \%$ trypsin/HBSS diluted $1: 4$ in serum-free DMEM for 45 minutes at $37^{\circ} \mathrm{C}$. $0.25 \%$ trypsin/PBS was then added to remove adherent microglia, and cells were replated in DMEM containing $2 \% \mathrm{HI}-\mathrm{FBS}$ at a density of 250,000 per well in 6-well plates.

\section{Phagocytosis Assay}

The phagocytosis assay was modified from previous studies. ${ }^{31-33}$ After overnight incubation in serum-free DMEM in the absence or presence of $100 \mathrm{nmol} / \mathrm{L}$ CX3CL1 (chemokine domain; R\&D Systems, Minneapolis, MN), Nile Red fluorescent microspheres (Invitrogen) washed in PBS containing $1 \mathrm{mg} / \mathrm{ml}$ BSA were added to the cells for 90 minutes. Cells were then extensively washed with PBS and fixed in $2 \%$ paraformaldehyde. The numbers of phagocytosed microspheres per cell were counted from random fields totaling 60-100 cells on an inverted microscope. The results were tabulated as mean \pm SEM and compared between genotypes using an unpaired $t$-test. Concentration of CX3CL1 used in the study has been shown to promote microglial survival ${ }^{34}$ and cell adhesion in vitro. ${ }^{35}$

To confirm uptake, cells plated on coverslips were immunostained with antibody against Iba1. After permeabilization with $0.1 \%$ PBST for 10 minutes at room temperature, cells were blocked in 5\% normal goat serum in PBS containing $0.3 \%$ Triton $\mathrm{X}-100$ for one hour at room temperature. Cells were then incubated with rabbit polyclonal Iba1 antibody (Wako) diluted 1:1000 in blocking buffer for 1 hour at room temperature, washed with PBS, incubated with Alexa 648 conjugated anti-rabbit IgG secondary antibody (Invitrogen) for one hour at room temperature, washed with PBS, and coverslipped with Vectashield mounting media (Vector). Single plane images were taken using a Leica SP5 confocal microscope.

\section{Preparation of Fibrillar $A \beta$}

Unlabeled $A \beta_{1-42}$ (American Peptide Company, Sunnyvale, CA) or HiLyte 555-conjugated $A \beta_{1-42}$ (AnaSpec, Fremont, CA) was diluted $1 \mathrm{mg} / \mathrm{ml}$ in $\mathrm{dd}_{2} \mathrm{O}$ and fibrillarized for 24 hours at $37^{\circ} \mathrm{C}$ as previously described. ${ }^{29}$ Control $A \beta_{42-1}$ peptide (Invitrogen), composed of same amino acids as $A \beta_{1-42}$ but in reverse sequence, was prepared in the same manner. 


\section{Stereotaxic Intracerebral A $\beta$ Microinjection}

Five- to seven-month-old $\mathrm{C} \times 3 \mathrm{Cr}^{+/+}$and $\mathrm{C} \times 3 \mathrm{Cr}^{-1-}$ were deeply anesthetized with ketamine/xylazine cocktail (100/10 mg/kg) and immobilized in a Kopf stereotaxic apparatus. A $0.5-\mathrm{mm}$ burr hole was drilled in the skull, and $2 \mu$ l of fibrillar $A \beta_{1-42}$ containing solution was injected at coordinates anteroposterior: $-1.0 \mathrm{~mm}$, lateral: $2.0 \mathrm{~mm}$, and dorsoventral: $1.0 \mathrm{~mm}$ with respect to bregma in the right cortex using a $10-\mu$ l Hamilton syringe. Some animals were injected with $2 \mu$ l of $A \beta_{42-1}$-containing solution at mirroring coordinates on the left cortex, providing an internal control. Mice were sacrificed 48 hours after injection and prepared for histology as described above. Coronal sections containing the needle track were immunostained for Iba1 (and for $A \beta$ using the 6E10 antibody in animals in which unlabeled $A \beta_{1-42}$ or $A \beta_{42-1}$ was injected) and visualized using appropriate Alexa dye-conjugated secondary antibodies. Iba1-positive microglia within 50 $\mu \mathrm{m}$ of the needle track were counted and examined for the presence of intracellular $A \beta$ in confocal Z-stacks spanning 20-30 $\mu \mathrm{m}$ in depth to calculate percent phagocytic microglia. Four $A \beta_{1-42}$ injected brains and three $A \beta_{42-1}$ injected brains were analyzed per genotype. The results were tabulated as mean \pm SEM and compared using an unpaired $t$-test. Unconjugated and HiLyte 555-conjugated $A \beta_{1-42}$ injections triggered identical microglial reactions (data not shown), and thus the results were combined into a single group. Furthermore, $\mathrm{A} \beta_{42-1}$-injected $\mathrm{C} \times 3 \mathrm{Cr}^{+/+}$and $\mathrm{C} \times 3 \mathrm{Cr}^{-1-}$ controls showed no significant differences in microglial counts (data not shown). Finally, control sections incubated with fluorescent anti-mouse IgG secondary antibodies reveled no specific labeling (data not shown), thereby ruling out nonspecific mouse IgG binding at the injection site.

\section{Results}

\section{CX3CR1 Deficiency Results in Reduced A $\beta$ Deposition in APPPS1 Mice}

APPPS1 mouse line coexpresses APP K670M/N671L and PS1 L166P mutations under the control of the neuronspecific Thy 1 promoter and exhibits early and robust $A \beta$ deposition beginning at $6-8$ weeks of age in the cortex and 3-4 months of age in the hippocampus. ${ }^{21}$ As reported previously, nearly all plaques are fibrillar. There is also marked microglial activation around the $A \beta$ deposits from the earliest time-points.

Cx3cr1 knockout animals were bred to the rapid-onset APPPS1 mouse model of AD to generate the following genotypes: APPPS1;C $\times 3 \mathrm{Cr}^{+/+}$, APPPS $1 ; \mathrm{C} \times 3 \mathrm{Cr}^{+1-}$, and APPPS 1;C $\times 3 \mathrm{Cr}^{-1-}$. Brain sections from four-month-old mice were stained with Thioflavine $S$, a fluorescent dye specific for fibrillar $A \beta$. Consistent with published reports, APPPS $1 ; C \times 3 \mathrm{Cr}^{+/+}$controls exhibited numerous fibrillar $A \beta$ deposits in the cortex and hippocampus (Figure 1A). Surprisingly, however, APPPS1;C $\times 3 \mathrm{Cr}^{+/-}$(Figure 1B) and APPPS $1 ;{\mathrm{C} \times 3 \mathrm{Cr}^{-1-}}^{-}$(Figure 1C) animals demon-
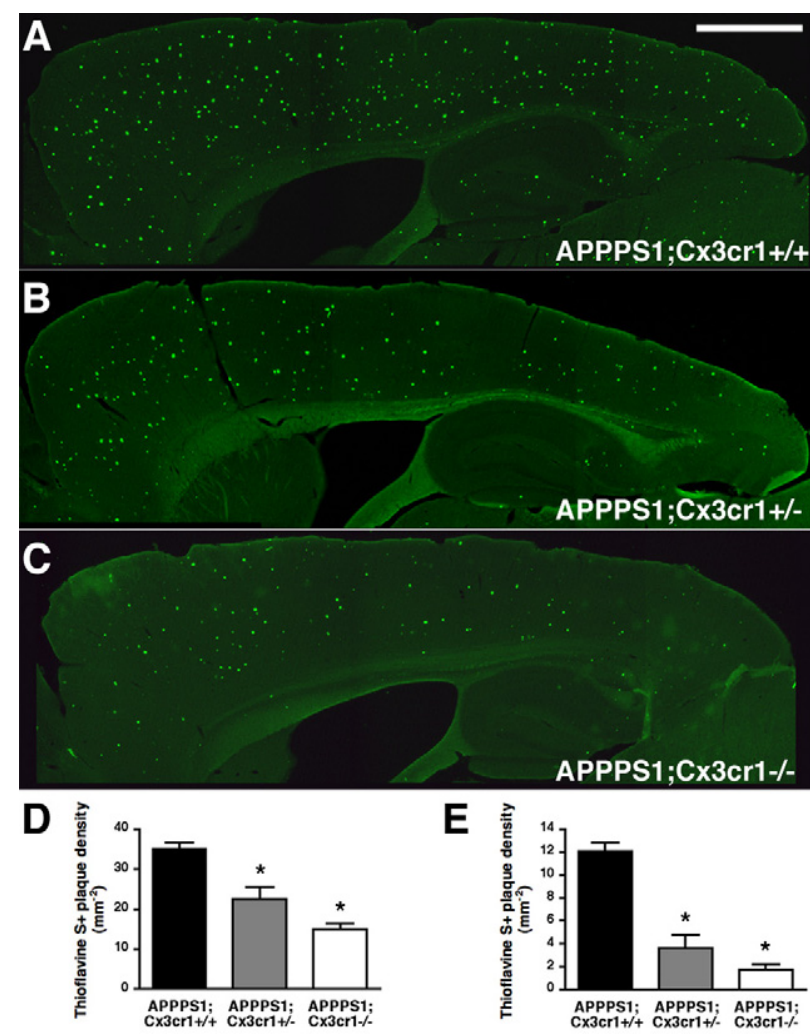

E

$\mathbf{F}$
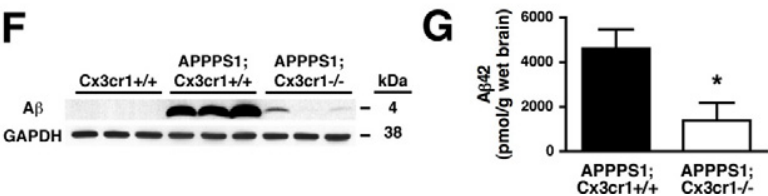

Figure 1. Gene dose-dependent reduction in fibrillar $\mathrm{A} \beta$ deposition in the APPPS1 mouse model of AD with CX3CR1 deficiency. Brain sections $(30 \mu \mathrm{m})$ from APPPS1;C $\times 3 \mathrm{Cr}^{+/+}(\mathbf{A}, n=7)$, APPPS1;Cx3Cr1 $1^{+/-}(\mathbf{B}, n=6)$, and APPPS1; $C x 3 \mathrm{Crl}^{-1-}(\mathbf{C}, n=7)$ mice at 4 months of age were stained with Thioflavine S. A series of low-power images (Scale bar $=1 \mathrm{~mm}$ ) were used to reconstruct the cortex and hippocampus from four sections from each animal. As expected based on the published literature, ${ }^{21}$ APPPS $1 ; C \times 3 c r 1^{+/+}$ animals exhibit abundant fibrillar $\mathrm{A} \beta$ deposition throughout the cortex with reduced $\mathrm{A} \beta$ deposition in the hippocampus $(\mathbf{A})$. By contrast, age-matched APPPS $1 ; C_{3} 3 \mathrm{CrI}^{+-}$(B) and APPPS1;CX3Cr1 ${ }^{-/-}$(C) animals exhibited a gene dose-dependent reduction in fibrillar $\mathrm{A} \beta$ deposition throughout the cortex and hippocampus. Quantification of Thioflavine S staining in the cortex (D) and hippocampus (E) across all animals revealed a statistically significant decrease in APPPS1 mice with either one or two copies of Cx3cr1 loss of function alleles when compared with age-matched APPPS1;C $\mathrm{Crr}_{3}^{+/+}$controls $\left({ }^{*} P<0.001\right)$. Notably, there was also a significant difference in $\mathrm{A} \beta$ deposition in the cortex between APPPS $1 ; \mathrm{C} \times 3 \mathrm{Cr}^{+/-}$and APPPS1; $\mathrm{C} \times 3 \mathrm{Cr}^{-1-}$ genotypes $(P<0.05)$. To confirm results obtained using Thioflavine S staining, Western blots of brain extracts from $\mathrm{C} \times 3 \mathrm{Cr}^{+/+}$, APPPS1; $C \times 3 \mathrm{Cr}^{+/+}$, and APPPS1; $\mathrm{C} \times 3 \mathrm{Cr}^{-/-}$animals were probed with antibodies to human $\mathrm{A} \beta$ and GAPDH as a loading control. Consistent with Thioflavine $S$ staining, APPPS $1 ; C x 3 \mathrm{Cr} 1^{-/-}$brains exhibited lower steady-state A $\beta$ levels when compared with age-matched APPPS1;C $x 3 \mathrm{Cr}^{+/+}$controls $(\mathbf{F})$. Furthermore, ELISAs performed on APPPS1;C $\times 3 \mathrm{Cr}^{+/+}(n=6)$ and APPPS1; $\mathrm{CX3Cr1^{-1- }}$ brain homogenates $(n=5)$ revealed reduced $\mathrm{A} \beta 42$ levels in CX3CR1-deficient animals $\left(\mathbf{G} ;{ }^{*} P<0.05\right)$

strated a gene dose-dependent reduction in Thioflavine S-positive $A \beta$ deposits in both the cortex as well as the hippocampus. In a quantitative analysis of fibrillar $A \beta$ burden, cortical Thioflavine $S$ positive $A \beta$ deposition was reduced by $35 \%$ in APPPS $1 ; C \times 3 \mathrm{Cr}^{+/-}$and by $57 \%$ in APPPS1;C $\times 3 \mathrm{Cr}^{-1-}$ mice when compared to APPPS1; $\mathrm{C} \times 3 \mathrm{Cr} 1^{+/+}$controls $(P<0.001$; Figure 1D). The APPPS1; $\mathrm{C} \times 3 \mathrm{Cr}^{-1-}$ mice demonstrated significantly reduced cor- 
tical deposition when compared to APPPS $1 ; \mathrm{C} 3 \mathrm{Cr}^{+/-}$ mice, indicating a gene dose-dependent effect $(P<$ 0.05). A $\beta$ deposition was also reduced in the hippocampus by $70 \%$ and $85 \%$ in the APPPS $1 ; C \times 3 \mathrm{Cr}^{+1-}$ and APPPS $1 ; C \times 3 \mathrm{Cr}^{-1-}$ animals $(P<0.001)$, when compared to control mice (Figure 1E). To determine whether the $A \beta$ deposits recognized by Thioflavine $S$ were representative of the total $A \beta$ within the brain, Western blots of $\mathrm{C} \times 3 \mathrm{Cr}^{+/+}$, APPPS1; $\mathrm{C} \times 3 \mathrm{Cr}^{+/+}$, and APPPS $1 ; \mathrm{C} \times 3 \mathrm{Cr}^{-1-}$ brain extracts were probed with the human-specific anti-A $\beta$ monoclonal antibody 6 E10 (Figure 1F). Confirming results obtained with Thioflavine S, APPPS1;CX3Cr1 ${ }^{-1-}$ brains exhibited drastically reduced levels of biochemically extracted $A \beta$ when compared to APPPS1; $C \times 3 \mathrm{Cr}^{+/+}$brains. In support of the Thioflavine S straining, ELISA analysis revealed reduced $A \beta 42$ levels in APPPS1;CX3Cr1 ${ }^{-1-}$ brains (1375 $\pm 803 \mathrm{pmol} / \mathrm{g}$ wet brain; Figure $1 \mathrm{G}$ ) when compared to APPPS1;C $\times 3 \mathrm{Cr}^{+/+}$brains (4608 $\pm 861 \mathrm{pmol} / \mathrm{g}$ wet brain; Figure 1G). Finally, 6E10 immunohistochemistry also confirmed a gene dose-dependent reduction $A \beta$ deposits in the cortex (see Supplemental Figure S1 at http://ajp.amjpathol.org) and hippocampus (data not shown). Taken together, these data indicate that CX3CR1 deficiency results in a gene dosedependent reduction in A $\beta$ deposition in the APPPS 1 mouse model of $A D$.

\section{CX3CR1 Deficiency Results in Reduced A $\beta$ Deposition in R1.40 Mice}

To address the effect of CX3CR1 deficiency in another $A D$ mouse model, we bred $C \times 3 c r 1$ knockout animals to the R1.40 mouse model of AD. The R1.40 transgene is a full genomic copy of the human APP gene expressing the K670M/N671L mutation carried on a yeast artificial chromosome. The R1.40 transgenic mouse line develops gradual $A D$-like $A \beta$ pathology, exhibiting both diffuse and fibrillar $A \beta$ deposition beginning at $14-16$ months of age in the cortex and 18-20 months of age in the hippocampus. ${ }^{36}$ Notably, fibrillar $A \beta$ deposits in $\mathrm{R} 1.40$ mice are associated with reactive microglia.

Brain sections from R1.40;Cx3 $\mathrm{Cr}^{+/+}$, R1.40; $\mathrm{C} \times 3 \mathrm{Cr}^{+/-}$, and R1.40;CX3Cr1 ${ }^{-1-}$ animals at 20-24 months of age were stained with Thioflavine $S$ to visualize fibrillar $A \beta$. R1.40; $\mathrm{C} \times 3 \mathrm{Cr}^{+/+}$controls exhibited abundant Thioflavine $S$ positive fibrillar $A \beta$ deposits in the cortex (see Supplemental Figure S2 at $h$ ttp://ajp.amjpathol.org). Similar to the results in CX3CR1-deficient APPPS1 mice, R1.40; $\mathrm{C} \times 3 \mathrm{Cr}^{+/-}$and $\mathrm{R} 1.40 ; \mathrm{C} \times 3 \mathrm{Cr}^{-1-}$ animals also demonstrated a gene dose-dependent reduction in Thioflavine S-positive A $\beta$ deposits in the cortex. Quantification of the total number of Thioflavine S-positive $A \beta$ deposits in the cortex revealed that $\mathrm{R} 1.40 ; \mathrm{C} \times 3 \mathrm{Cr}^{+/-}$and $\mathrm{R} 1.40$; $\mathrm{C} \times 3 \mathrm{Cr}^{-1-}$ exhibited markedly fewer cortical Thioflavine S-positive plaques when compared to site-matched brain regions in $\mathrm{R} 1.40 ; \mathrm{C} \times 3 \mathrm{Cr} 1^{+/+}$mice $(P<0.05)$. Taken together, these data indicate that CX3CR1 deficiency results in a gene dose-dependent reduction in $A \beta$ deposition in mouse models of $A D$, regardless of the kinetics of deposition.

\section{CX3CR1 Deficiency Reduces A $\beta$-Associated Dystrophic Neurites in APPPS1 and R1.40 Mice}

To assess neuronal integrity in the current studies, several additional experiments were performed. First, TUNEL and cleaved caspase 3 staining of brain sections from CX3CR1-deficient APPPS1 and R1.40 animals did not reveal any gross alterations in neurodegeneration (data not shown), consistent with previous studies demonstrating no overt neurodegeneration in either the APPPS1 or R1.40 animals. ${ }^{21,36}$ Second, additional staining with antibodies for dystrophic neurites, including APP (antibody CT15) and tau phosphorylation (antibody AT8) revealed a reduction in staining in both the APPPS1;C $\times 3 \mathrm{Cr}^{-1-}$ (See Supplemental Figure S3 at http://ajp.amjpathol.org) and $\mathrm{R} 1.40 ; \mathrm{C} \times 3 \mathrm{Cr}^{-1-}$ animals (data not shown) that likely reflects the reduction in $A \beta$ deposition observed in these mice.

\section{CX3CR1 Deficiency Does Not Alter APP Levels or APP Processing}

One potential explanation for the alterations in $A \beta$ deposition observed in the APPPS $1 ; \mathrm{C} 3 \mathrm{Cr}^{+/-}$and APPPS1; $\mathrm{C} \times 3 \mathrm{Cr}^{-1-}$ animals was that either APP transgene expression or APP processing was altered. To examine this possibility, brain extracts from two-month-old APPPS1; $\mathrm{C} \times 3 \mathrm{Cr}^{+/+}$, APPPS1;C $\times 3 \mathrm{Cr}^{+/-}$, and APPPS1;C $\times 3 \mathrm{Cr}^{-1-}$ animals were analyzed by Western blot for the levels of holo-APP and APP CTFs. No significant differences in the steady state levels of holo-APP were observed in the samples from three different genotypes (Figure 2, A [top] and B). The steady-state levels of APP CTFs, including $\mathrm{CTF} \beta$, the direct precursor of $A \beta$, were unaltered (Figure 2, $\mathrm{A}$ [middle] and $\mathrm{C}$ ). Similar results were also obtained in the R1.40 mouse model of AD with CX3CR1 deficiency (see Supplemental Figure S4 at http://ajp.amjpathol.org). In addition, there were no alterations in the steady-state

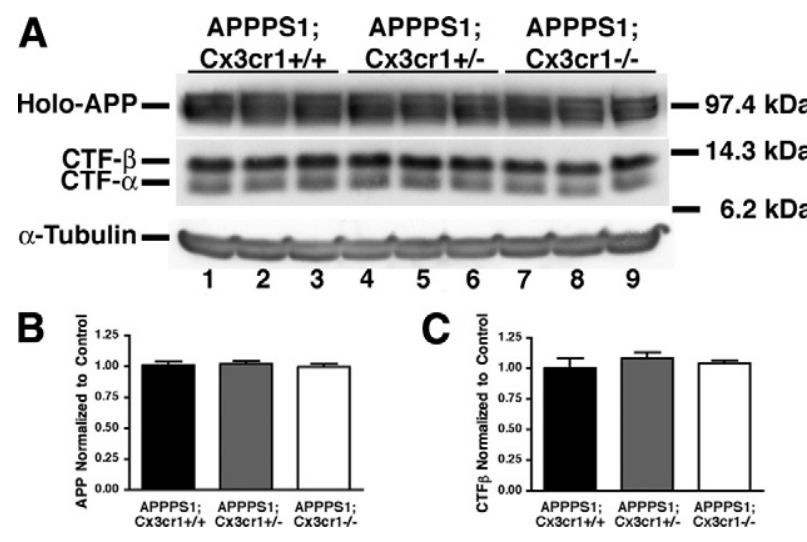

Figure 2. Lack of effect of CX3CR1 genotype on APP processing. A: Western blots of brain extracts from the APPPS $1 ; \mathrm{Cx}_{3} \mathrm{Cr}^{+/+}$(Lanes 1-3), APPPS1; $\mathrm{C}_{3} 3 \mathrm{Cr}^{+/-}$(Lanes 4-6). and APPPS1;C $\mathrm{CSCr}^{-/-}$(Lanes 7-9) animals were probed with an antibody to the $C$ terminus of APP (top two panels) and subsequently stripped and reprobed with an antibody against $\alpha$-tubulin as a loading control. Shown on the right is the approximate size in $\mathrm{kDa}$. B: Relative levels of holo-APP were quantified $(n=8)$ from each genotype by normalizing the intensity values of APP to $\alpha$-tubulin. C: Relative values of $\operatorname{CTF} \beta$ were quantified similarly averaging the values of APP CTF $\beta$ to $\alpha$-tubulin. No significant differences were observed in the relative levels of either holo-APP or CTF $\beta$ between genotypes. 
levels of brain A $\beta$ in pre-depositing APPPS1 and R1.40 mice (data not shown). Taken together, these results indicate that the differences in $A \beta$ deposition observed in this study are not due to altered expression or processing of APP by neurons and instead suggest involvement of brain microglia, where CX3CR1 is exclusively expressed.

\section{CX3CR1 Deficiency Leads to an Altered Neuroinflammatory Milieu}

One potential explanation for the alterations in A $\beta$ deposition observed in the APPPS1;C $\times 3 \mathrm{Cr}^{+1-}$ and APPPS1; CX3 $\mathrm{Cr}^{-1-}$ animals was that loss of CX3CL1-CX3CR1 signaling leads to altered microglial activation. To examine this possibility, brain sections from four-month-old wild-type C57BL/6J mice (Figure 3, A and B), APPPS1; $\mathrm{C} \times 3 \mathrm{Cr}^{+/+}$(Figure 3, C and D), APPPS1;C $\times 3 \mathrm{Cr}^{+/-}$(Figure 3, E and F), and APPPS1;Cx3Cr1 ${ }^{-1-}$ (Figure 3, G and $H)$ were immunostained with either an antibody to CD68 (Figure 3, A, C, E, and G), a marker for macrophages (including microglia-derived macrophages), or CD45 (Figure 3, B, D, F, and $\mathrm{H}$ ), a marker for cells of the hematopoietic lineage which is moderately up-regulated in activated microglia. Sections were subsequently counterstained with the amyloid dye Congo Red to visualize dense-core $A \beta$ deposits. Wild-type non-transgenic sections demonstrated no Congo Red-positive deposits and sparse CD68 (Figure 3A) and CD45 immunoreactivity (Figure 3B). CD68- and CD45-postive microglia are closely associated with Congo Red-positive deposits in all APPPS1 genotypes (Figure 3, insets). CD68 immunoreactivity was qualitatively reduced in APPPS $1 ; \mathrm{C} \times 3 \mathrm{Cr}^{+/-}$ (Figure 3E) and APPPS 1; $\mathrm{C} \times 3 \mathrm{Cr}^{-1-}$ animals (Figure 3G) compared to APPPS1; $\mathrm{C} \times 3 \mathrm{Cr}^{+/+}$controls (Figure $3 \mathrm{C}$ ). By contrast, CD45 immunoreactivity between the APPPS1; $\mathrm{C} \times 3 \mathrm{Cr}^{+/+}$(Figure 3D), APPPS1;C $\times 3 \mathrm{Cr}^{+/-}$(Figure 3F) and APPPS1;CX3 $\mathrm{Cr}^{-1-}$ (Figure 3H) genotypes appeared relatively unchanged. These data suggest that CX3CR1 deficiency alters the microglial activation program in reaction to dense-core $A \beta$ deposits.

To determine whether microglial CX3CR1 signaling mediates non-cell-autonomous effects in other inflammatory cells in the brain, sections from four-month-old wildtype, APPPS1;C $\times 3 \mathrm{Cr}^{+/+}$, and APPPS1;C $\times 3 \mathrm{Cr}^{-1-}$ animals were stained with an antibody to GFAP, an astrocytic marker and Congo Red (see Supplemental Figure S5 at http://ajp.amjpathol.org). As expected, wildtype controls exhibited no Congo Red-positive $A \beta$ deposits and GFAP immunoreactivity was limited to the meninges and perivascular regions. By contrast, APPPS1; $\mathrm{C} \times 3 \mathrm{Cr}^{+/+}$mice exhibited abundant Congo Red-positive $\mathrm{A} \beta$ deposits that were ringed by numerous GFAP-positive astrocytes. In addition to a substantial reduction in the amount of $\mathrm{A} \beta$ deposition in the APPPS1;CX3Cr1 ${ }^{-1-}$ animals (Figure 1), there was also significantly reduced GFAP immunoreactivity. Taken together, these results indicate that, in addition to alterations in microglial activation, there is also reduced astrocytosis in CX3CR1deficient APPPS1 mice, although both of these alterations could be due to the reduced $A \beta$ deposition observed.

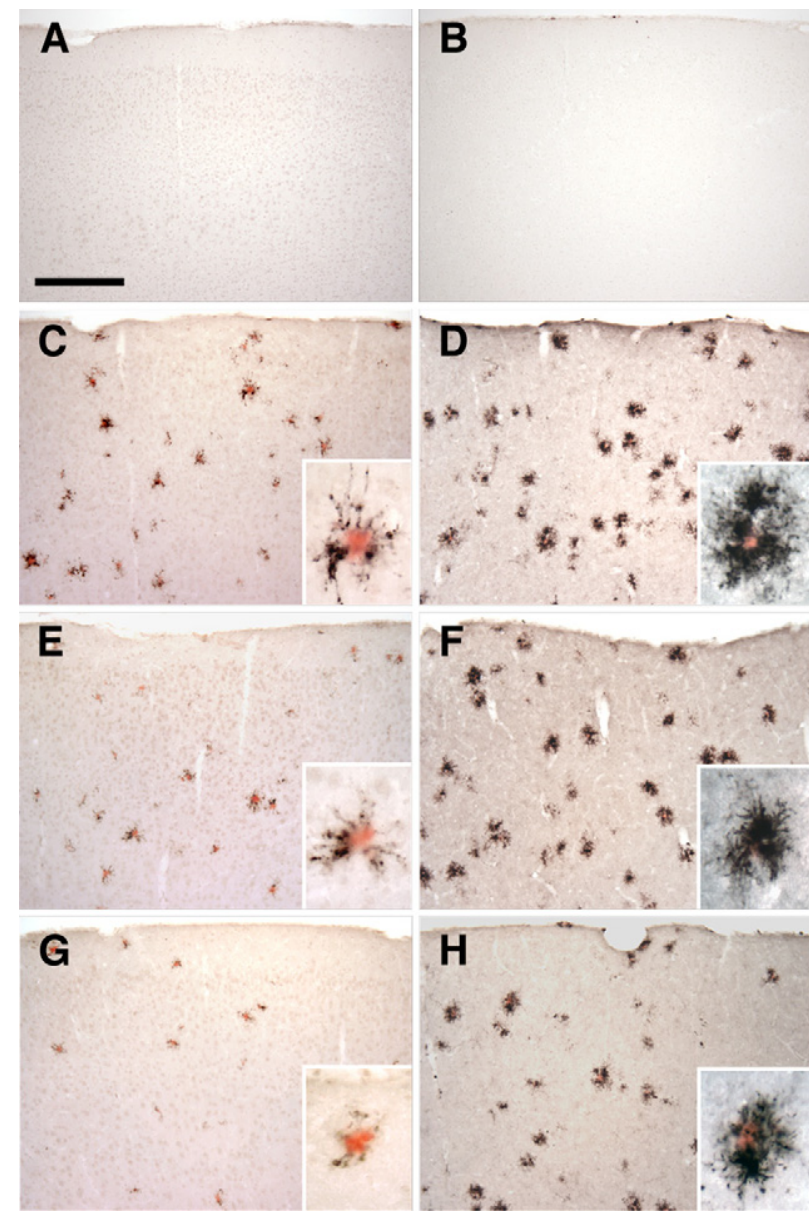

Figure 3. Altered expression of microglial markers in the APPPS1 mouse model of $\mathrm{AD}$ with CX3CR1 deficiency. Brain sections $(30 \mu \mathrm{m})$ from wild-type C57BL/6J $(\mathbf{A}$ and $\mathbf{B}), \operatorname{APPPS} 1 ; C \times 3 \mathrm{Cr}^{+/+}\left(\mathbf{C}\right.$ and D), APPPS1;C $\times 3 \mathrm{Cr}^{+/-}(\mathbf{E}$ and $\mathbf{F})$, and APPPS1; $\mathrm{C}_{3} \mathrm{Cr}^{-1-}(\mathbf{G}$ and $\mathbf{H})$ mice at 4 months of age were immunostained with antibodies to either $\mathrm{CD} 68$, a marker for phagocytic microglia/macrophages $(\mathbf{A}, \mathbf{C}, \mathbf{E}$, and $\mathbf{G})$, or CD 45, a marker for cells of hematopoietic lineage which is up-regulated in activated microglia $(\mathbf{B}, \mathbf{D}, \mathbf{F}$, and $\mathbf{H})$. Sections were also counterstained with Congo Red, a dye specific for dense-core $\mathrm{A} \beta$ deposits. Wild-type sections contained no Congo Red-positive deposits and rare CD68 (A) and CD 45 (B) immunoreactivity. Consistent with the published literature, APPPS1; C $x 3 \mathrm{Cr}^{+/+}$animals show abundant CD68 (C) and CD 45 immunoreactivity (D), especially in the immediate vicinity of Congo Red-positive $\mathrm{A} \beta$ deposits (insets).

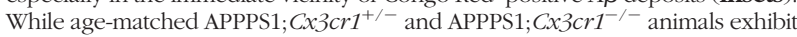
gene dose-dependent reduction in CD68 immunoreactivity compared to APPPS1; $\mathrm{C} 33 \mathrm{Cr}^{+/+}$controls (E and $\mathbf{G}$, respectively), CD45 immunoreactivity is relatively unchanged in APPPS1;C $33 \mathrm{Cr}^{+/-}$and APPPS1;C $3 \mathrm{Cr}^{-1-}$ animals compared with APPPS1;Cx3cr1 $1^{+/+}$controls (F and $\mathbf{H}$, respectively). As expected, higher magnification revealed that CD68- and CD45-positive microglia are mostly clustered around Congo Red-positive $\mathrm{A} \beta$ deposits (insets). Scale bar $=250 \mu \mathrm{m}$.

\section{CX3CR1 Deficiency Leads to Reductions in Plaque-Associated Microglia}

Our immunohistochemical studies suggested that CX3CR1 deficiency leads to reductions in CD68-positive microglia. This finding could be due to the reduced $A \beta$ deposition observed in CX3CR1-deficient mice. To address this possibility, we quantified the number of microglia on a per-plaque basis. Brain sections from fourmonth-old APPPS1;C $\times 3 \mathrm{Cr}^{+/+}$(Figure 4, A-C), APPPS1; $\mathrm{C} \times 3 \mathrm{Cr}^{+/-}$(Figure 4, D-F), and APPPS1;C $\times 3 \mathrm{Cr}^{-1-}$ mice (Figure 4, G-I) were coimmunostained with monoclonal anti-A $\beta$ antibody, 4G8 (red; Figure 4, A, D, and G) and an 

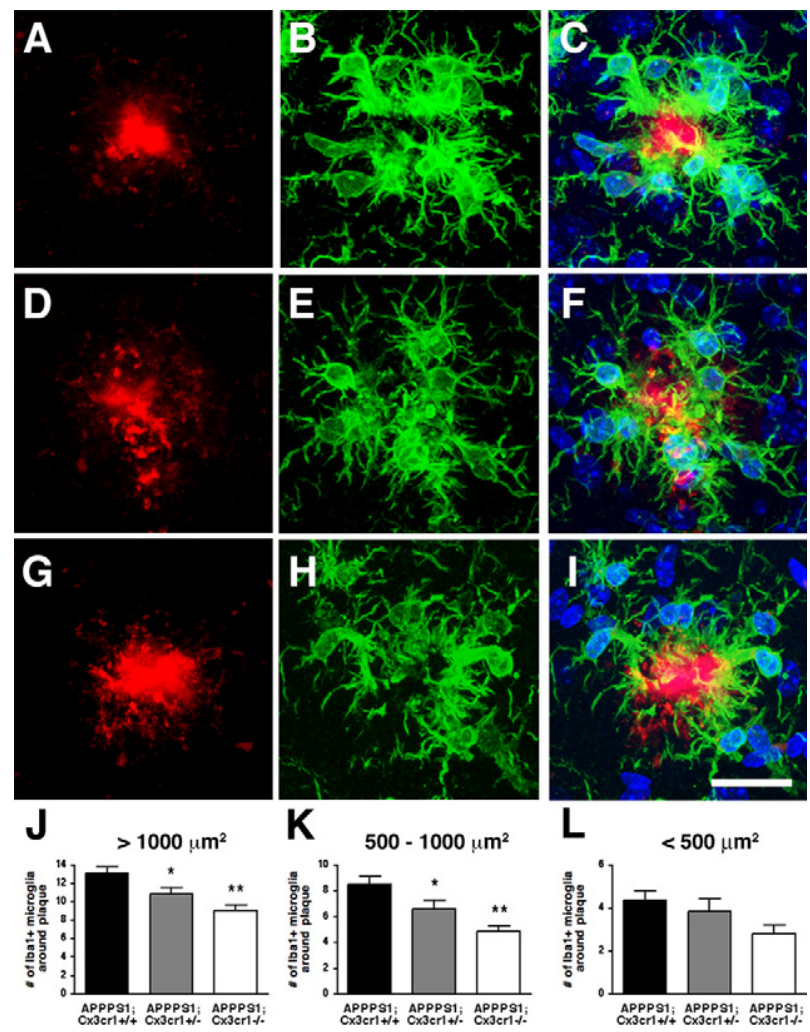

Figure 4. Reduced plaque-associated microglia in the APPPS1 mouse model of $\mathrm{AD}$ with CX3CR1 deficiency. Brain sections $(30 \mu \mathrm{m})$ from APPPS1; $\mathrm{Cx}_{3} \mathrm{Cr}^{+/+}(\mathbf{A}-\mathbf{C})$, APPPS1;C $\times 3 \mathrm{Cr}^{+/-}(\mathbf{D}-\mathbf{F})$, and APPPS1;C $\times 3 \mathrm{Cr}^{-/-}(\mathbf{G}-\mathbf{I})$ mice at 4 months of age were immunostained with monoclonal $\mathrm{A} \beta$ antibody 4G8 (red; $\mathbf{A}, \mathbf{D}$, and $\mathbf{G}$ ), with an antibody against the pan-microglial marker Iba1 (green; $\mathbf{B}, \mathbf{E}$, and $\mathbf{H}$ ), and counterstained with the nuclear TO-PRO-3 dye (blue, $\mathbf{C}, \mathbf{F}$, and $\mathbf{I}$ ). Confocal microscopy was used to obtain maximum projections reconstructed from Z-stacks spanning 20-30 $\mu \mathrm{m}$ in depth. As expected, APPPS1;C $x 3 \mathrm{Cr}^{+/+}$controls exhibit extensive accumulation of Iba1-positive microglia around senile plaques (A-C). However, age-matched APPPS1;C $\times 3 \mathrm{Cr}^{+/-}(\mathbf{D}-\mathbf{F})$ and APPPS1;C $\times 3 \mathrm{cr}^{-/-}$animals $(\mathbf{G}-\mathbf{I})$ exhibit gene dose-dependent reduction in the number of Iba1-positive microglia surrounding the senile plaques. The number of Iba1-positive microglia associated with senile plaques in the three genotypes was quantified in three nonadjacent sections from each of the four animals per genotype. APPPS1 mice with either one or two copies of $\mathrm{Cx} 3 \mathrm{cr} 1$ loss-of-function alleles exhibited a statistically significant reduction in microglia surrounding both large $\left(>1000 \mu \mathrm{m}^{2} ; \mathbf{J}\right)$, medium $\left(>500 \mu \mathrm{m}^{2},<1000 \mu \mathrm{m}^{2} ; \mathbf{K}\right)$, and small $\left(<500 \mu \mathrm{m}^{2}\right.$ L) A $\beta$ deposits when compared to age-matched APPPS $1 ; C \times 3 \mathrm{Cr}^{+/+}$controls ( ${ }^{*} P<0.05 ;{ }^{* * *} P<0.001$, respectively). The APPPS1; $\mathrm{C} \times 3 \mathrm{Cr} 1^{+/-}$and APPPS1; $\mathrm{C} \times 3 \mathrm{Cr}^{-1-}$ genotypes exhibited a statistically significant difference in microglial accumulation around medium A $\beta$ deposits $(P<0.05)$, suggesting a gene dose-dependent effect. $n=35$ for all analyses. Scale bar $=25 \mu \mathrm{m}$.

antibody against the pan-microglial marker Iba1 (green; Figure 4, B, E, and $\mathrm{H}$ ). Sections were subsequently counterstained with a TO-PRO-3 nuclear dye (blue; Figure 4C, $F$, and I) and imaged via confocal microscopy to obtain Z-stacks. We observed a gene dose-dependent reduction in the number of plaque-associated microglia in the cortex of APPPS1;C $\times 3 \mathrm{Cr}^{+/-}$(Figure 4, D-F) and APPPS1;C $\times 3 \mathrm{Cr}^{-1-}$ (Figure 4, G-I) animals when compared to APPPS $1 ; \mathrm{C} 3 \mathrm{Cr}^{+/+}$controls (Figure 4, A-C).

To evaluate the possibility that CX3CR1 signaling to microglia might mediate a differential response to larger plaques, $A \beta$ deposits were grouped based on area and numbers of Iba1-positive microglia whose nuclei or primary processes directly overlapped $A \beta$ deposits in a given tissue section were quantified. Large plaques $\left(>1000 \mu \mathrm{m}^{2}\right)$ in APPPS1;CX3Cr1 ${ }^{+/+}$controls exhibited an average of $\sim 13$ plaque associated microglia, whereas those in APPPS1;C $\times 3 \mathrm{Cr}^{+1-}$ and APPPS1;C $\times 3 \mathrm{Cr}^{-1-}$ animals exhibited only $\sim 11$ and $\sim 9$ plaque-associated microglia, respectively (Figure $4 \mathrm{~J}$ ). For medium plaques (>500 $\mu \mathrm{m}^{2}$ and $<1000 \mu \mathrm{m}^{2}$ ), APPPS1;C $\times 3 \mathrm{Cr}^{+1-}$ and APPPS 1; $\mathrm{C} \times 3 \mathrm{Cr}^{-1-}$ mice demonstrated an average of $\sim 7$ and $\sim 5$ plaque associated microglia, respectively, which was significantly lower than $\sim 9$ plaque associated microglia in the medium plaques of APPPS $1 ; \mathrm{C}_{3} 3 \mathrm{Cr}^{+/+}$controls (Figure 4K). In addition, for medium plaques, APPPS 1; $\mathrm{C} \times 3 \mathrm{Cr}^{-1-}$ mice exhibited a significant decrease in plaque associated microglia when compared to APPPS 1; $\mathrm{C} \times 3 \mathrm{Cr}^{+/-}$mice, indicating a gene dose-dependent effect. For small plaques $\left(<500 \mu \mathrm{m}^{2}\right)$, differences were not statistically significant among the genotypes (Figure 4L). In summary, these results indicate that CX3CR1 deficiency reduces the number of microglia around $A \beta$ deposits in a gene dose-dependent manner in the APPPS1 mouse model of AD.

\section{CX3CR1 Deficiency Leads to Altered Expression of Inflammatory Cytokines/Chemokines}

To gain insight into the potential mechanisms underlying the concomitant reduction in $A \beta$ deposition and plaqueassociated microglia, the expression levels of various cytokines and chemokines was examined by quantitative RT-PCR. Total brain RNA from four-month-old B6 controls, APPPS1;C $\times 3 \mathrm{Cr}^{+1+}$, APPPS $1 ; \mathrm{C} \times 3 \mathrm{Cr}^{+/-}$, and APPPS 1;C $\times 3 \mathrm{Cr}^{-1-}$ mice was reverse transcribed and assayed in triplicate for expression of the CCL2, CX3CL1, IFN $\gamma$, IL $1 \beta$, IL4, IL6, IL 10, and TNF $\alpha$ mRNAs using TaqMan probes. Expression of both TNF $\alpha$ and CCL2 mRNAs were increased in APPPS $1 ; \mathrm{C} 3 \mathrm{Cr}^{+/+}$mice at four months of age relative to $\mathrm{B} 6$ control mice (Figure 5 , A and $C$, respectively). Notably, age-matched APPPS1; $\mathrm{C} \times 3 \mathrm{Cr}^{+1-}$ and APPPS1;C $\times 3 \mathrm{Cr}^{-1-}$ mice demonstrated reduced expression levels of both TNF $\alpha(P<0.001)$ and CCL2 mRNAs $(P<0.01)$ relative to APPPS1;C $\mathrm{C} 3 \mathrm{Cr} 1^{+/+}$ mice (Figure 5, A and $C$, respectively). By contrast, expression of IL $1 \beta$ mRNA was up-regulated in APPPS1; Cx3Cr1 ${ }^{+/-}$and APPPS1; $C \times 3 \mathrm{Cr}^{-1-}$ animals $(P<0.05$ and $P<0.01$, respectively; Figure $5 \mathrm{~B}$ ) as previously reported in other neuroinflammatory models. ${ }^{13}$ Levels of mRNAs for CX3CL1, IFN $\gamma$, IL4, IL6, and IL10 did not
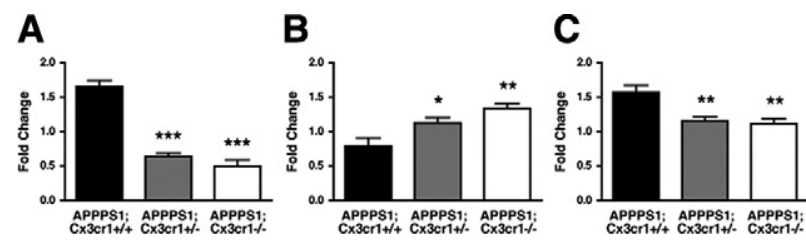

Figure 5. Altered expression of inflammatory markers in CX3CR1-deficient APPPS1 mouse model of AD. Relative mRNA expression of TNF $\alpha$ (A), IL1 $\beta$ (B), and MCP-1 (C) in APPPS1;C $x 3 c r 1^{+/+}(n=7), \operatorname{APPPS1} C \operatorname{Cx} 3 \mathrm{cr} 1^{+/-}(n=$ 8), and APPPS1;Cx3Cr1 $1^{-1-}(n=9)$ mice at 4 months. The mRNA levels for each cytokine were normalized to the mRNA levels of GAPDH and expressed relative to that of nontransgenic $\mathrm{C} 57 \mathrm{BL} / 6 \mathrm{~J}$ mice. Results from APPPS1; $\mathrm{C} \times 3 \mathrm{Cr}^{+/-}$and APPPS1;C $\times 3 \mathrm{Cr}^{-1-}$ animals were compared with results from age-matched APPPS $1 ; C \times 3 c r 1^{+/+}$controls $\left({ }^{*} P<0.05,{ }^{* * *} P<0.01,{ }^{* * * * *} P<\right.$ $0.001)$. 

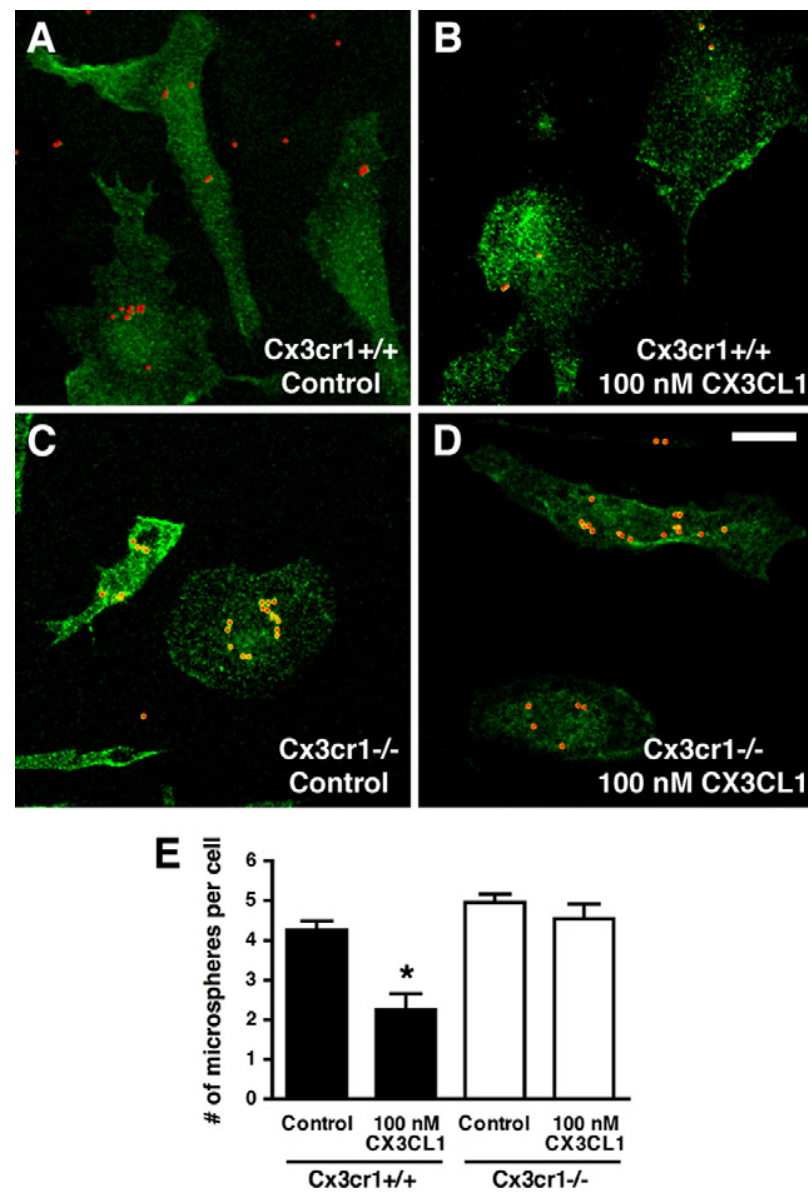

Figure 6. CX3CL1-CX3CR1 signaling inhibits microglial phagocytosis $\mathrm{C}_{3} 3 \mathrm{Cr}^{+/+}(\mathbf{A}$ and $\mathbf{B})$ and $\mathrm{C} \times 3 \mathrm{Cr}^{-1-}(\mathbf{C}$ and $\mathbf{D})$ primary microglia were incubated in the absence (A and $\mathbf{C}$ ) or presence (B and $\mathbf{D})$ of CX3CL1 (100 $\mathrm{nmol} / \mathrm{L}$ ) overnight, and fluorescent microspheres were added for 90 minutes The cells were fixed and stained with antibody against Iba1 and visualized with Alexa 648-conjugated secondary antibody (pseudo-colored green; A-D). Single-plane confocal images are shown. CX3CL1-treated $\mathrm{C} \times 3 \mathrm{cr} 1^{+/+}$ microglia exhibited reduced numbers of phagocytosed microspheres per cell when compared with untreated $C \times 3 \mathrm{Cr}^{+/+}$and CX3CL1-treated $\mathrm{C} \times 3 \mathrm{Cr}^{-1-}$ microglia $\left(\mathbf{E} ;{ }^{*} P<0.05\right) . n=3$ for each group. Scale bar $=15 \mu \mathrm{m}$.

exhibit significant differences among the genotypes relative to B6 control mice (data not shown). These results suggest that there are alterations in the expression of the chemokines/cytokines CCL2, IL1 $\beta$, and TNF $\alpha$ in the brains of the APPPS 1 mouse model of AD with CX3CR1 deficiency.

\section{CX3CR1 Signaling Inhibits Microglial Phagocytosis}

Our observations that reduced amyloid deposition in CX3CR1-deficient mice, along with less microglia per plaque, were somewhat counterintuitive. One potential explanation is that CX3CL1-CX3CR1 signaling could alter the phagocytic capacity of microglia. To examine this possibility, primary microglia from $\mathrm{C} \times 3 \mathrm{Cr} 1^{+/+}$(Figure 6, A and $\mathrm{B}$ ) and $\mathrm{C} \times 3 \mathrm{Cr}^{-1-}$ animals (Figure 6, $\mathrm{C}$ and D) were assessed for their ability to phagocytose fluorescent microspheres. On average, $\mathrm{C} \times 3 \mathrm{cr} 1^{+/+}$microglia phagocytosed $\sim 4$ microspheres per cell (Figure 6, A and E)

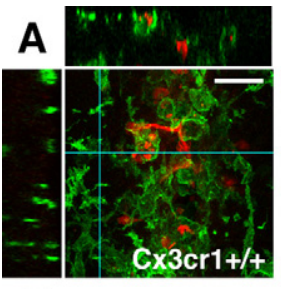

D

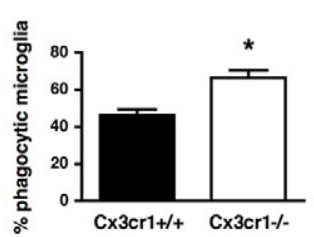

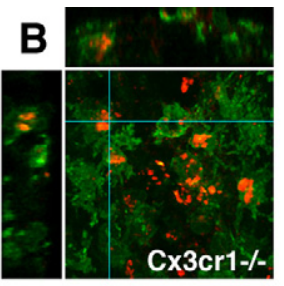

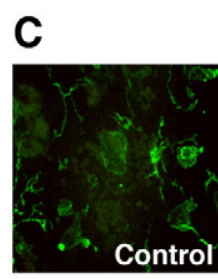

E

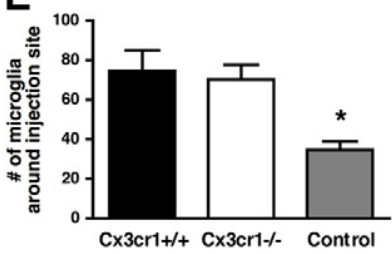

Figure 7. Enhanced $A \beta$ phagocytosis in CX3CR1-deficient mice. Five- to 7-month-old $\mathrm{Cx} 3 \mathrm{Cr}^{+/+}(n=4 ; \mathbf{A})$ and $\mathrm{Cx} 3 \mathrm{cr}^{-/-}(n=4 ; \mathbf{B})$ mice were injected with fibrillar $\mathrm{A} \beta_{1-42}$ (red; HiLyte 555-conjugated) or with control $\mathrm{A} \beta_{42-1}$ peptide $(n=6 ; \mathbf{C})$. Sections $(30 \mu \mathrm{m})$ containing the needle track were immunostained with an antibody against Iba1 and visualized with Alexa 648-conjugated secondary antibody (pseudo-colored green; A-C). From confocal Z-stacks spanning $20-30 \mu \mathrm{m}$ in depth, we obtained maximum projections (A-C) and slices in the $\mathrm{x}$ - and $\mathrm{y}$-plane showing $\mathrm{A} \beta$ internalization ( $\mathbf{A}$ and $\mathbf{B}$ ). The number of microglia (E) and percent phagocytic microglia (D) within $50 \mu \mathrm{m}$ of the needle track were quantified. $\mathrm{Cx}_{3} \mathrm{CrI}^{-1-}$ microglia exhibited enhanced $\mathrm{A} \beta$ phagocytosis when compared with control $\mathrm{C}_{3} 3 \mathrm{Cr}^{+/+}$microglia $\left({ }^{*} P<0.01 ; \mathbf{D}\right)$, whereas the number of microglia around the injection site did not significantly differ between genotypes (E) Furthermore, as expected, control $\mathrm{A} \beta_{42-1}$ peptide injection triggered significantly reduced microglial reaction compared to fibrillar $\mathrm{A} \beta_{1-42}$ injection (C and $\left.\mathbf{E} ;{ }^{*} P<0.05\right)$.

whereas $\mathrm{CX} 3 \mathrm{CL} 1$-treated $\mathrm{C} \times 3 \mathrm{Cr} 1^{+/+}$microglia phagocytosed only $\sim 2$ microspheres per cell (Figure $6, \mathrm{~B}$ and $\mathrm{E}$; $P<0.05)$. $C \times 3 \mathrm{Cr}^{-1-}$ microglia demonstrated equivalent phagocytic responses either with (Figure 6, C and E) or without fractalkine treatment (Figure 6, D and E), indicating that CX3CL1-mediated inhibition of microglial phagocytic capacity required CX3CR1 signaling. These results suggest that alterations in CX3CL1-CX3CR1 signaling can lead to altered phagocytic capabilities of microglia and could account for the apparent discrepancy between the reduced numbers of microglia per plaque and reduced $A \beta$ deposition observed in CX3CR1-deficient animals.

\section{CX3CR1 Deficiency Enhances A $\beta$ Phagocytosis}

Our in vitro data suggested that CX3CL1-CX3CR1 signaling inhibits microglial phagocytic capacity. To examine whether loss of CX3CL1-CX3CR1 signaling could lead to enhanced uptake of $A \beta$ in vivo and thus account for findings in the CX3CR1-deficient AD mouse models, fibrillar $A \beta_{1-42}$ was stereotactically injected into the cortices of $\mathrm{C} \times 3 \mathrm{Cr}^{+/+}$(Figure $7 \mathrm{~A}$ ) and $\mathrm{C} \times 3 \mathrm{Cr}^{-1-}$ animals (Figure $7 \mathrm{~B}$ ). On average, $46 \%$ of $\mathrm{C} \times 3 \mathrm{Cr}^{+/+}$microglia within $50 \mu \mathrm{m}$ of the needle track contained fibrillar $A \beta$, whereas $66 \%$ of $C \times 3 \mathrm{Cr}^{-1-}$ microglia contained $\mathrm{A} \beta$ (Figure 7D; $P<0.01$ ). Notably, however, both $C \times 3 c r 1^{+/+}$ and $\mathrm{C} \times 3 \mathrm{Cr}^{-1-}$ microglia accumulated in similar numbers near the fibrillar $A \beta_{1-42}$ injection sites (Figure 7E; $P<$ $0.05)$, suggesting that there was no significant alteration in the ability of microglia to migrate to the $A \beta$ injection site. Stereotaxic injections with a control $A \beta_{42-1}$ peptide 
triggered significantly reduced microglial reaction in both the $\mathrm{C} \times 3 \mathrm{Cr}^{+/+}$and $\mathrm{C}^{+} 3 \mathrm{Cr}^{-1-}$ brains (Figure 7, C and $\mathrm{E}$; $P<0.05$ ), indicating that the microglial responses were specific to fibrillar $A \beta_{1-42}$. In addition, the $C \times 3 \mathrm{Cr}^{-1-}$ microglia in the $A \beta_{1-42}$ injected animals exhibited a different morphology, with a more rounded appearance, than either $\mathrm{C} \times 3 \mathrm{Cr} 1^{+/+} \mathrm{A} \beta_{1-42}$ injected animals or $\mathrm{A} \beta_{42-1}$ injected controls (compare Figure $7 \mathrm{~B}$ to $7 \mathrm{~A}$ and $7 \mathrm{C}$ ), which is consistent with an altered phagocytic capacity of these cells. These data demonstrate that blocking CX3CL1CX3CR1 signaling leads to enhanced uptake of fibrillar $A \beta$ within microglia and could thus explain the reductions in $A \beta$ deposition observed in CX3CR1-deficient APPPS1 and R1.40 animals.

\section{Discussion}

The findings presented here offer insights into the role of microglial CX3CR1 signaling in the development of amyloid pathology in the APPPS1 and R1.40 mouse models. Previous studies showed that in the CNS, CX3CL1 is expressed by neurons and signals to CX3CR1 on microglia. ${ }^{13,14}$ Furthermore, recent reports implicated impaired CX3CL1-CX3CR1 signaling in neurodegeneration. First, in various models of neurodegeneration, including the 1-methyl-4-phenyl-1,2,3,6-tetrahydropyridine model of Parkinson's disease; a transgenic mouse model of amyotrophic lateral sclerosis; and induction of neuroinflammation via systemic lipopolysaccharide administration, CX3CR1 deficiency resulted in increased neuronal cell death and worsening of phenotypes via mechanisms cell-autonomous to microglia. ${ }^{13}$ Second, Cx3cr1 knockout mice exhibited age-dependent subretinal microglial accumulation and retinal degeneration. ${ }^{37,38}$ Third, the V249I and T280M polymorphisms in CX3CR1 are associated with altered risk for age-related macular degeneration in humans. ${ }^{17,18}$ Taken together these results support a role of CX3CL1-CX3CR1 signaling to microglia in modulating neurodegenerative disease phenotypes.

The present studies tested the hypothesis that CX3CR1 deficiency would alter AD phenotypes in transgenic mouse models of the disease. Unexpectedly, CX3CR1 deficiency in two different mouse models of AD leads to an amelioration of the amyloid pathology in both the rapid onset APPPS1 (Figure 1) as well as the gradual onset R1.40 (see Supplemental Figure S2 at http:// ajp.amjpathol.org) mouse models of AD. To examine the effects of CX3CR1 deficiency on neurons, TUNEL and cleaved caspase 3 staining of brain sections from CX3CR1-deficient APPPS1 and R1.40 animals revealed no evidence for any gross neurodegeneration (data not shown) while staining with antibodies for dystrophic neurites (CT15 and AT8) revealed a reduction in staining in both the APPPS1;CX3 $\mathrm{Cr}^{-1-}$ (see Supplemental Figure S3 at http://ajp.amjpathol.org) and R1.40;CX3Cr1 ${ }^{-1-}$ animals (data not shown) that appears to reflect the reduction in $A \beta$ deposition observed in these mice.

Significantly, we also observed a gene dose-dependent effect of CX3CR1 deficiency, with heterozygous $\mathrm{Cx} 3 \mathrm{Cr} 1$ mice exhibiting an intermediate phenotype. This suggests that alterations in CX3CR1 signaling could influence human AD pathogenesis, a hypothesis that could be tested via genetic association studies with CX3CR1 variants implicated in age-related macular degeneration or via therapeutic strategies aimed at reducing CX3CR1 signaling. The finding of a heterozygous phenotype also has implications for previous studies in the field, as heterozygous $\mathrm{C} \times 3 \mathrm{Cr} 1^{\mathrm{GFP} /+}$ mice have been used to study microglial dynamics in AD mouse models. ${ }^{3,5}$

Multiple mechanisms could account for the reduction in $A \beta$ deposition observed in the CX3CR1-deficient mouse models of AD. To determine whether CX3CR1 deficiency altered APP production or processing, we showed that the levels of steady-state APP and APP CTFs remained unchanged in CX3CR1 deficient APPPS1 and R1.40 mice (Figure 2 and see Supplemental Figure S4 at http://ajp.amjpathol.org). Given that CX3CR1 is exclusively expressed by microglia within the brain and the effects of CX3CR1 deficiency are autonomous to microglia, ${ }^{13}$ we postulated that the effect of CX3CR1 deficiency on $A \beta$ deposition was mediated via alterations within microglia.

Analysis of microglial markers demonstrated a gene dose-dependent reduction in both the numbers of Iba1positive microglia surrounding individual $A \beta$ deposits (Figure 4) as well as staining for the microglial activation marker CD68 (Figure 3) in CX3CR1-deficient APPPS1 mice. Thus, our results showed a reduction in the amount of $A \beta$ deposition and alterations in the activation of microglia surrounding the $A \beta$ deposits. These observations were unexpected, as it seemed more likely that reduced amyloid burden might be mediated by augmented microglial activation.

In addition to alterations in microglial activation, we also observed a substantial reduction in astrocytosis in CX3CR1-deficient APPPS1 animals (see Supplemental Figure S5 at http://ajp.amjpathol.org), suggesting that there is an altered neuroinflammatory milieu within these animals. However, this was not unexpected given that there is reduced $A \beta$ deposition in these animals. In addition, because CX3CR1 is exclusively expressed by microglia in the murine CNS, ${ }^{13,15}$ the reduced astrogliosis is by definition a secondary response to primary alterations in microglia. Thus, while we cannot formally exclude the role of astrocytes in the reduced $A \beta$ deposition observed in CX3CR1-deficient animals, the current studies point to enhanced $A \beta$ phagocytosis by $C \times 3 \mathrm{Cr}^{-1-}$ microglia as the more proximal and significant contributor.

Interestingly, we also found selective alterations in the levels of brain mRNAs for specific cytokines/chemokines depending on the genotype of the animal (Figure 5). Similar to previous findings in $A D$ brains and mouse models, ${ }^{39-42}$ the levels of CCL2 and TNF $\alpha$ mRNAs were elevated in the APPPS $1 ; \mathrm{C} \times 3 \mathrm{Cr}^{+/+}$mouse brain. Notably, CX3CR1 deficiency reduced the levels of CCL2 and TNF $\alpha$ mRNA to that observed in the non-transgenic controls, while brain levels of IL $1 \beta$ mRNA were increased.

In addition, in vitro phagocytosis assay revealed that CX3CL1-CX3CR1 signaling regulates the phagocytic capacity of microglia (Figure 6). CX3CL1 treatment of primary microglia led to a $50 \%$ reduction in the number of 
phagocytosed microspheres in wild-type $\mathrm{C} \times 3 \mathrm{Cr}^{+/+}$ primary microglia. Importantly, the phagocytic capacity of $\mathrm{C} \times 3 \mathrm{Cr}^{-1-}$ primary microglia did not change with CX3CL1 treatment, indicating that the reduced microglial phagocytosis observed is mediated by CX3CR1 signaling. We did not observe an enhancement of phagocytosis in $\mathrm{C}_{3} \mathrm{Crr}^{-1-}$ compared to untreated $\mathrm{C} \times 3 \mathrm{Cr}^{+/+}$microglia.

Finally, we confirmed that microglial $A \beta$ phagocytosis was enhanced in CX3CR1-deficient APPPS1 animals (Figure 7). Sixty-six percent of $\mathrm{C} \times 3 \mathrm{Cr}^{-1-}$ microglia around fibrillar $A \beta_{1-42}$ injection sites were phagocytic, whereas only $46 \%$ of $\mathrm{C} \times 3 \mathrm{Cr}^{+/+}$microglia were phagocytic. However, $\mathrm{C} \times 3 \mathrm{Cr}^{+/+}$and $\mathrm{C} \times 3 \mathrm{Cr}^{-/-}$microglia accumulated in similar numbers around the injection sites, suggesting that microglial migration was not impaired by CX3CR1 deficiency.

In the $A D$ brain, microglia accumulate at the site of newly formed $A \beta$ deposits via migration or local proliferation and may help restrict plaque growth. ${ }^{4,5}$ We hypothesize that the drastic reduction in $A \beta$ deposition in CX3CR1 deficient R1.40 and APPPS1 animals is due to alterations in the ability of CX3CR1 deficient microglia to i) remove $A \beta$, and/or ii) accumulate around $A \beta$ deposits via proliferation and/or migration. The postulated sequence of events is that $A \beta$ accumulation is associated with neuronal stress and CX3CL1 proteolytic release, ${ }^{43}$ leading to reduced phagocytosis by $\mathrm{C}_{3} \mathrm{Cr}^{+/+}$but not CX3 $\mathrm{Cr}^{-1-}$ microglia.

\section{Microglial Removal of $A \beta$}

Recent in vivo imaging studies using mouse models of $A D$ have shown that microglia may help restrict the growth of senile plaques. ${ }^{4,5}$ However, considerable evidence suggests that in vivo $\mathrm{A} \beta$ removal is critically dependent on microglial activation status. ${ }^{33,44-47}$ Microglia can exist in multiple activation states that are determined by the local stimuli for activation and reflected in production of specific cytokines and chemokines. ${ }^{48}$ Within the AD brain, there is a chronic activation of microglia associated with inflammatory cytokines including TNF $\alpha$ that can substantially block of ability of the microglia to remove ${ }^{47,49,50}$ or degrade $\mathrm{A} \beta{ }^{51,52}$ Recent studies demonstrated that overexpression of IL $1 \beta$, an inflammatory cytokine leads to reduced $A \beta$ pathology in mouse models of $A D{ }^{9,53}$

One partial explanation for our results is that CX3CR1 deficiency alters the microglial activation status and enhances $A \beta$ clearance. In support of this possibility, TNF $\alpha$ mRNA levels were selectively down-regulated in CX3CR1 deficient APPPS1 animals, and TNF $\alpha$ has been shown to directly reduce microglial expression of $A \beta$-degrading enzymes such as insulin-degrading enzyme and neprily$\sin .^{51,52}$ Furthermore, IL1 $\beta$ mRNA levels were significantly increased in a gene dose-dependent manner in the CX3CR1-deficient APPPS1 animals, and previous studies demonstrated that IL $1 \beta$ overexpression enhances $A \beta$ clearance. ${ }^{9,53}$ Finally, mRNA levels of MCP-1, which promotes microglia-mediated $A \beta$ oligomerization, ${ }^{54}$ was reduced in CX3CR1-deficient APPPS1 ani- mals and thus could lead to reduced $A \beta$ oligomerization/ deposition. These observations suggest that CX3CR1 deficiency leads to a cytokine environment that harnesses the beneficial effects of microglial activation in response to $A \beta$. Notably, increased IL $1 \beta$ levels were also observed in $C \times 3 \mathrm{cr} 1$ knockout mice in response to lipopolysaccharide injections, where it led to enhanced neurotoxicity. ${ }^{13}$ Indeed, the effect of CX3CR1 deficiency appears to depend on the nature of the CNS insult as recent studies demonstrated that $\mathrm{C} \times 3 \mathrm{cr} 1$ knockout mice exhibit smaller infarcts after transient middle cerebral artery occlusion. ${ }^{19,20}$

Another relevant observation is that CX3CR1 signaling directly blunts microglial phagocytosis and might prevent effective $A \beta$ clearance. In support of this hypothesis, our in vitro and in vivo data demonstrate that CX3CL1CX3CR1 signaling inhibits microglial phagocytosis, including fibrillar $A \beta$. Notably, CX3CL1 is found in high concentrations in both normal and diseased $\mathrm{CNS}^{55}$ and our results suggest that CX3CL1-CX3CR1 signaling establishes a permissive environment for $A \beta$ deposition in the AD brains and transgenic mouse models by downregulating the microglial phagocytic response toward $A \beta$. Enhanced phagocytosis in the absence of CX3CR1 signaling could also help to explain the heterogeneity of phenotypes in CX3CR1-deficient CNS disease models. Depending on the nature of the CNS insult, increased microglial phagocytosis may ameliorate ${ }^{46}$ or worsen pathology. ${ }^{56}$

Finally, a recent study provided evidence that gancyclovir-mediated depletion of microglia expressing thymidine kinase had no demonstrable effect on $A \beta$ pathology in two mouse models of AD. ${ }^{57}$ While these studies suggest that relatively short term depletion of microglia had only negligible effect on $A \beta$ deposition, numerous other studies have suggested that altering the proliferation, ${ }^{58}$ signaling, ${ }^{8,9,11}$ and migration ${ }^{7,59}$ of microglia directly impact development of $A \beta$ pathology. Taken together, these data suggest multiple redundant pathways that regulate $A \beta$ clearance and deposition in different disease states and experimental conditions.

\section{Microglial Proliferation/Migration}

In mouse models of $A D$, the numbers of plaque-associated microglia increase over time and restrict the growth in plaque volume. ${ }^{4,5}$ However, in other situations, excess microglial accumulation appears to exacerbate $A \beta$ pathology. ${ }^{7}$ In CX3CR1-deficient animals, there was a gene dose-dependent reduction in number of microglia associated with $A \beta$ deposition. We postulate that our observations could be explained by the following: i) enhanced microglial clearance of $A \beta$, so that the retention of cells per plaque was reduced; ii) alterations in microglial proliferation/cell death; and/or iii) alterations in migration of microglia/macrophages to $A \beta$ deposits.

Microglia surrounding $A \beta$ deposits undergo extensive turnover in a mouse model of $A D$, exhibiting both apoptosis and proliferation. ${ }^{60}$ Interestingly, CX3CR1 signaling inhibits microglial apoptosis via Fas-mediated mech- 
anisms in vitro. ${ }^{34}$ Future studies will be needed to determine whether the reduction in microglial number associated with $A \beta$ deposition in CX3CR1-deficient animals is due to alterations in microglial cell death or proliferation. However, our preliminary analysis suggests that microglial proliferation and cell death were unaltered in APPPS1 mice deficient for CX3CR1 as assessed via bromodeoxyuridine incorporation and cleaved caspase 3 labeling, respectively (data not shown).

Another possibility is altered migration of either microglia or peripheral monocytes/macrophages to $A \beta$ deposits in the CX3CR1-deficient animals. Various genetically modified mouse models have convincingly demonstrated the role for other chemokines/cytokine pathways in altering the accumulation of mononuclear phagocytes (monocytes, macrophages, and microglia) and $A \beta$ pathology, including CCR2 ${ }^{59}$ and IL $1 \beta .{ }^{9}$ However, in the present studies, despite the reduction in the number of microglia around the $A \beta$ deposits in CX3CR1-deficient APPPS1 animals, there was a significant reduction in $A \beta$ deposition, consistent with an enhanced capacity of microglia to remove $A \beta$. Accordingly, the simplest interpretation of our data are that fewer $\mathrm{C} \times 3 \mathrm{Cr}^{-1-}$ microglia were associated with each plaque due to their enhanced phagocytic capacity, leading to the associated findings of reduced $A \beta$ deposition and fewer microglia per plaque.

A recent study (published while the current study was under review) suggested that CX3CR1 deficiency can prevent neuronal loss in the $3 \times \mathrm{Tg}$ mouse model of AD. ${ }^{61}$ A $1.8 \%$ loss of neurons per month observed in the $3 \times \mathrm{Tg}$ mouse model by two-photon microscopy was prevented in the CX3XR1 deficient 3xTg animals. However, this study examined $3 \times \mathrm{Tg}$ animals at 4-6 months, an age at which there is no extracellular deposition of $A \beta$ but instead abundant intracellular $A \beta$ immunoreactivity. At the single age examined, the levels of $A \beta$ remain relatively unchanged in these animals, although their assessment of insoluble $A \beta$ appears to show a non-significant reduction in the knockout mice.

Fuhrmann et al argue that these studies show that the lack of CX3CR1 does not "interfere with the $A \beta$-phagocytosing activity of microglia." However, our studies demonstrate that CX3CR1 deficiency reduces extracellular $A \beta$ deposition in two different mouse models of $A D$ via a mechanism that likely involves enhanced phagocytic clearance of extracellular $A \beta$ fibrils. Thus, the apparent discrepancy in the results of the two studies may be reflective of the cellular location of the $A \beta$ aggregates and is supported by our findings that the steady-state levels of $A \beta$ in predepositing CX3CR1-deficient APPPS1 and R1.40 animals remained unchanged (data not shown).

Furthermore, we did not observe any obvious alterations in neurodegeneration in the APPPS $1 ; \mathrm{C} \times 3 \mathrm{Cr}^{-1-}$ and $\mathrm{R} 1.40 ; \mathrm{C}_{3} \mathrm{Cr}^{-1-}$ animals, consistent with previous studies demonstrating no overt neurodegeneration in either the APPPS1 or R1.40 animals. ${ }^{21,36}$ Notably, similar types of studies also did not detect robust neuronal loss in aged $3 \times \mathrm{Tg}$ animals, ${ }^{62}$ and it remains to be determined how the neuronal loss observed by Fuhrmann et al via two photon microscopy relates to the amyloid toxicity observed in the 3xTg, APPPS1 and R1.40 mouse models. Notably, the reduction in $A \beta$ deposition in the CX3CR1deficient APPPS1 and R1.40 mice also led to a reduction in the formation of dystrophic neurites, which perhaps could, in turn, impact local neurodegeneration. Clearly, additional studies are warranted to further define the role of CX3CL1/CX3CR1 signaling in AD pathogenesis

\section{Acknowledgments}

We thank Mathias Jucker (University of Tuebingen, Germany) for the APPPS1 mice; Gary Landreth (Case Medical School, Cleveland) and Mathias Jucker for helpful comments about the manuscript; Nicole Maphis, Cathleen Chang and Grahame Kidd for technical support; and Edward Koo (University of California San Diego, San Diego, CA) for providing the CT15 antibody.

\section{References}

1. Wyss-Coray $\mathrm{T}$, Mucke L: Inflammation in neurodegenerative disease-a double-edged sword. Neuron 2002, 35:419-432

2. Akiyama H, Barger S, Barnum S, Bradt B, Bauer J, Cole GM, Cooper NR, Eikelenboom P, Emmerling M, Fiebich BL, Finch CE, Frautschy S, Griffin WS, Hampel H, Hull M, Landreth G, Lue L, Mrak R, Mackenzie IR, McGeer PL, O'Banion MK, Pachter J, Pasinetti G, Plata-Salaman C, Rogers J, Rydel R, Shen Y, Streit W, Strohmeyer R, Tooyoma I, Van Muiswinkel FL, Veerhuis R, Walker D, Webster S, Wegrzyniak B, Wenk G, Wyss-Coray T: Inflammation and Alzheimer's disease. Neurobiol Aging 2000, 21:383-421

3. Koenigsknecht-Talboo J, Meyer-Luehmann M, Parsadanian M, Garcia-Alloza M, Finn MB, Hyman BT, Bacskai BJ, Holtzman DM: Rapid microglial response around amyloid pathology after systemic antiAbeta antibody administration in PDAPP mice. J Neurosci 2008, 28:14156-14164

4. Bolmont T, Haiss F, Eicke D, Radde R, Mathis CA, Klunk WE, Kohsaka S, Jucker M, Calhoun ME: Dynamics of the microglial/amyloid interaction indicate a role in plaque maintenance. J Neurosci 2008 , 28:4283-4292

5. Meyer-Luehmann M, Spires-Jones TL, Prada C, Garcia-Alloza M, de Calignon A, Rozkalne A, Koenigsknecht-Talboo J, Holtzman DM, Bacskai BJ, Hyman BT: Rapid appearance and local toxicity of amyloid-beta plaques in a mouse model of Alzheimer's disease. Nature 2008, 451:720-724

6. Morgan D, Gordon MN, Tan J, Wilcock D, Rojiani AM: Dynamic complexity of the microglial activation response in transgenic models of amyloid deposition: implications for Alzheimer therapeutics. J Neuropathol Exp Neurol 2005, 64:743-753

7. Yamamoto M, Horiba M, Buescher JL, Huang D, Gendelman HE, Ransohoff RM, Ikezu T: Overexpression of monocyte chemotactic protein-1/CCL2 in beta-amyloid precursor protein transgenic mice show accelerated diffuse beta-amyloid deposition. Am J Pathol 2005, 166:1475-1485

8. Town T, Laouar Y, Pittenger C, Mori T, Szekely CA, Tan J, Duman RS Flavell RA: Blocking TGF-beta-Smad2/3 innate immune signaling mitigates Alzheimer-like pathology. Nat Med 2008, 14:681-687

9. Shaftel SS, Kyrkanides S, Olschowka JA, Miller JN, Johnson RE, O'Banion MK: Sustained hippocampal IL-1 beta overexpression mediates chronic neuroinflammation and ameliorates Alzheimer plaque pathology. J Clin Invest 2007, 117:1595-1604

10. Xiang Z, Ho L, Yemul S, Zhao Z, Qing W, Pompl P, Kelley K, Dang A, Teplow D, Pasinetti GM: Cyclooxygenase-2 promotes amyloid plaque deposition in a mouse model of Alzheimer's disease neuropathology. Gene Expr 2002, 10:271-278

11. Maier M, Peng Y, Jiang L, Seabrook TJ, Carroll MC, Lemere CA: Complement C3 deficiency leads to accelerated amyloid beta plaque deposition and neurodegeneration and modulation of the microglia/ 
macrophage phenotype in amyloid precursor protein transgenic mice. J Neurosci 2008, 28:6333-6341

12. Limatola C, Lauro C, Catalano M, Ciotti MT, Bertollini C, Di Angelantonio S, Ragozzino D, Eusebi F: Chemokine CX3CL1 protects rat hippocampal neurons against glutamate-mediated excitotoxicity. J Neuroimmunol 2005, 166:19-28

13. Cardona AE, Pioro EP, Sasse ME, Kostenko V, Cardona SM, Dijkstra IM, Huang D, Kidd G, Dombrowski S, Dutta R, Lee JC, Cook DN, Jung S, Lira SA, Littman DR, Ransohoff RM: Control of microglial neurotoxicity by the fractalkine receptor. Nat Neurosci 2006, 9:917-924

14. Harrison JK, Jiang Y, Chen S, Xia Y, Maciejewski D, McNamara RK, Streit WJ, Salafranca MN, Adhikari S, Thompson DA, Botti P, Bacon $\mathrm{KB}$, Feng L: Role for neuronally derived fractalkine in mediating interactions between neurons and CX3CR1-expressing microglia, Proc Natl Acad Sci USA 1998, 95:10896-10901

15. Jung S, Aliberti J, Graemmel P, Sunshine MJ, Kreutzberg GW, Sher A, Littman DR: Analysis of fractalkine receptor CX(3)CR1 function by targeted deletion and green fluorescent protein reporter gene insertion. Mol Cell Biol 2000, 20:4106-4114

16. Bazan JF, Bacon KB, Hardiman G, Wang W, Soo K, Rossi D, Greaves DR, Zlotnik A, Schall TJ: A new class of membrane-bound chemokine with a CX3C motif. Nature 1997, 385:640-644

17. Tuo J, Smith BC, Bojanowski CM, Meleth AD, Gery I, Csaky KG, Chew $E Y$, Chan CC: The involvement of sequence variation and expression of CX3CR1 in the pathogenesis of age-related macular degeneration. FASEB J 2004, 18:1297-1299

18. Chan CC, Tuo J, Bojanowski CM, Csaky KG, Green WR: Detection of CX3CR1 single nucleotide polymorphism and expression on archived eyes with age-related macular degeneration. Histol Histopathol 2005, 20:857-863

19. Denes A, Ferenczi S, Halasz J, Kornyei Z, Kovacs KJ: Role of CX3CR1 (fractalkine receptor) in brain damage and inflammation induced by focal cerebral ischemia in mouse. J Cereb Blood Flow Metab 2008, 28:1707-1721

20. Soriano SG, Amaravadi LS, Wang YF, Zhou H, Yu GX, Tonra JR, Fairchild-Huntress V, Fang Q, Dunmore JH, Huszar D, Pan Y: Mice deficient in fractalkine are less susceptible to cerebral ischemiareperfusion injury. J Neuroimmunol 2002, 125:59-65

21. Radde R, Bolmont T, Kaeser SA, Coomaraswamy J, Lindau D, Stoltze L, Calhoun ME, Jaggi F, Wolburg H, Gengler S, Haass C, Ghetti B, Czech C, Holscher C, Mathews PM, Jucker M: Abeta42-driven cerebral amyloidosis in transgenic mice reveals early and robust pathology. EMBO Rep 2006, 7:940-946

22. Lamb BT, Sisodia SS, Lawler AM, Slunt HH, Kitt CA, Kearns WG Pearson PL, Price DL, Gearhart JD: Introduction and expression of the 400 kilobase amyloid precursor protein gene in transgenic mice [corrected]. Nat Genet 1993, 5:22-30

23. Lamb BT, Call LM, Slunt HH, Bardel KA, Lawler AM, Eckman CB, Younkin SG, Holtz G, Wagner SL, Price DL, Sisodia SS, Gearhart JD: Altered metabolism of familial Alzheimer's disease-linked amyloid precursor protein variants in yeast artificial chromosome transgenic mice. Hum Mol Genet 1997, 6:1535-1541

24. Lehman EJH, Kulnane LS, Lamb BT: Alterations in $\beta$-amyloid production and deposition in brain regions of two transgenic models. Neurobiol Aging 2003, 24:645-653

25. Lehman EJ, Kulnane LS, Gao Y, Petriello MC, Pimpis KM, Younkin L, Dolios G, Wang R, Younkin SG, Lamb BT: Genetic background regulates $\beta$-amyloid precursor protein processing and $\beta$-amyloid deposition in the mouse. Hum Mol Genet 2003, 12:2949-2956

26. Martin LJ, Sisodia SS, Koo EH, Cork LC, Dellovade TL, Weidemann A, Beyreuther K, Masters C, Price DL: Amyloid precursor protein in aged nonhuman primates. Proc Natl Acad Sci USA 1991, 88:1461-1465

27. Yang $\mathrm{Y}$, Varvel NH, Lamb BT, Herrup K: Ectopic cell cycle events link human Alzheimer's disease and amyloid precursor protein transgenic mouse models. J Neurosci 2006, 26:775-784

28. Andorfer C, Acker CM, Kress Y, Hof PR, Duff K, Davies P: Cell-cycle reentry and cell death in transgenic mice expressing nonmutant human tau isoforms J Neurosci 2005, 25:5446-5454

29. Reed-Geaghan EG, Savage JC, Hise AG, Landreth GE: CD14 and toll-like receptors 2 and 4 are required for fibrillar $\mathrm{A}\{$ beta\}-stimulated microglial activation. J Neurosci 2009, 29:11982-11992

30. Saura J, Tusell JM, Serratosa J: High-yield isolation of murine microglia by mild trypsinization. Glia 2003, 44:183-189

31. Koenigsknecht J, Landreth G: Microglial phagocytosis of fibrillar be- ta-amyloid through a beta1 integrin-dependent mechanism. J Neurosci 2004, 24:9838-9846

32. Kim DC, Kim SH, Jeong MW, Baek NI, Kim KT: Effect of rottlerin, a PKC-delta inhibitor, on TLR-4-dependent activation of murine microglia. Biochem Biophys Res Commun 2005, 337:110-115

33. Koenigsknecht-Talboo J, Landreth GE: Microglial phagocytosis induced by fibrillar beta-amyloid and IgGs are differentially regulated by proinflammatory cytokines. J Neurosci 2005, 25:8240-8249

34. Boehme SA, Lio FM, Maciejewski-Lenoir D, Bacon KB, Conlon PJ: The chemokine fractalkine inhibits Fas-mediated cell death of brain microglia. J Immunol 2000, 165:397-403

35. Haskell CA, Hancock WW, Salant DJ, Gao W, Csizmadia V, Peters W, Faia K, Fituri O, Rottman JB, Charo IF: Targeted deletion of CX(3)CR1 reveals a role for fractalkine in cardiac allograft rejection. J Clin Invest 2001, 108:679-688

36. Kulnane LS, Lamb BT: Neuropathological characterization of mutant amyloid precursor protein yeast artificial chromosome transgenic mice. Neurobiol Dis 2001, 8:982-992

37. Combadiere C, Feumi C, Raoul W, Keller N, Rodero M, Pezard A, Lavalette S, Houssier M, Jonet L, Picard E, Debre P, Sirinyan M, Deterre P, Ferroukhi T, Cohen SY, Chauvaud D, Jeanny JC, Chemtob S, Behar-Cohen F, Sennlaub F: CX3CR1-dependent subretinal microglia cell accumulation is associated with cardinal features of agerelated macular degeneration. J Clin Invest 2007, 117:2920-2928

38. Raoul W, Keller N, Rodero M, Behar-Cohen F, Sennlaub F, Combadiere C: Role of the chemokine receptor CX3CR1 in the mobilization of phagocytic retinal microglial cells. J Neuroimmunol 2008, 198:56-61

39. Ishizuka K, Kimura T, Igata-yi R, Katsuragi S, Takamatsu J, Miyakawa $\mathrm{T}$ : Identification of monocyte chemoattractant protein-1 in senile plaques and reactive microglia of Alzheimer's disease. Psychiatry Clin Neurosci 1997, 51:135-138

40. Simard AR, Soulet D, Gowing G, Julien JP, Rivest S: Bone marrowderived microglia play a critical role in restricting senile plaque formation in Alzheimer's disease. Neuron 2006, 49:489-502

41. Heneka MT, Sastre M, Dumitrescu-Ozimek L, Dewachter I, Walter J, Klockgether T, Van Leuven F: Focal glial activation coincides with increased BACE1 activation and precedes amyloid plaque deposition in APP[V717I] transgenic mice. J Neuroinflammation 2005, 2:22

42. Janelsins MC, Mastrangelo MA, Oddo S, LaFerla FM, Federoff HJ, Bowers WJ: Early correlation of microglial activation with enhanced tumor necrosis factor-alpha and monocyte chemoattractant protein-1 expression specifically within the entorhinal cortex of triple transgenic Alzheimer's disease mice. J Neuroinflammation 2005, 2:23

43. Chapman GA, Moores K, Harrison D, Campbell CA, Stewart BR Strijbos PJ: Fractalkine cleavage from neuronal membranes represents an acute event in the inflammatory response to excitotoxic brain damage. J Neurosci 2000, 20:RC87

44. Townsend KP, Town T, Mori T, Lue LF, Shytle D, Sanberg PR, Morgan D, Fernandez F, Flavell RA, Tan J: CD40 signaling regulates innate and adaptive activation of microglia in response to amyloid betapeptide. Eur J Immunol 2005, 35:901-910

45. Zelcer N, Khanlou N, Clare R, Jiang Q, Reed-Geaghan EG, Landreth GE, Vinters HV, Tontonoz P: Attenuation of neuroinflammation and Alzheimer's disease pathology by liver $x$ receptors. Proc Natl Acad Sci USA 2007, 104:10601-10606

46. Boissonneault V, Filali M, Lessard M, Relton J, Wong G, Rivest S: Powerful beneficial effects of macrophage colony-stimulating factor on beta-amyloid deposition and cognitive impairment in Alzheimer's disease. Brain 2009, 132:1078-1092

47. Shie FS, Montine KS, Breyer RM, Montine TJ: Microglial EP2 is critical to neurotoxicity from activated cerebral innate immunity. Glia 2005, $52: 70-77$

48. Ransohoff RM, Perry VH: Microglial physiology: unique stimuli, specialized responses. Annu Rev Immunol 2009, 27:119-145

49. Jimenez S, Baglietto-Vargas D, Caballero C, Moreno-Gonzalez I, Torres M, Sanchez-Varo R, Ruano D, Vizuete M, Gutierrez A, Vitorica $\mathrm{J}$ : Inflammatory response in the hippocampus of PS1M146L APP751SL mouse model of Alzheimer's disease: age-dependent switch in the microglial phenotype from alternative to classic. J Neurosci 2008, 28:11650-11661

50. Monsonego A, Zota V, Karni A, Krieger JI, Bar-Or A, Bitan G, Budson AE, Sperling R, Selkoe DJ, Weiner HL: Increased T cell reactivity to 
amyloid beta protein in older humans and patients with Alzheimer disease. J Clin Invest 2003, 112:415-422

51. Yamamoto M, Kiyota T, Walsh SM, Liu J, Kipnis J, Ikezu T: Cytokinemediated inhibition of fibrillar amyloid-beta peptide degradation by human mononuclear phagocytes. J Immunol 2008, 181:3877-3886

52. Shimizu E, Kawahara K, Kajizono M, Sawada M, Nakayama H: IL-4induced selective clearance of oligomeric beta-amyloid peptide(142) by rat primary type 2 microglia. J Immunol 2008, 181:6503-6513

53. Quinn J, Montine T, Morrow J, Woodward WR, Kulhanek D, Eckenstein F: Inflammation and cerebral amyloidosis are disconnected in an animal model of Alzheimer's disease. J Neuroimmunol 2003, 137:32-41

54. Kiyota T, Yamamoto M, Xiong H, Lambert MP, Klein WL, Gendelman HE, Ransohoff RM, Ikezu T: CCL2 accelerates microglia-mediated Abeta oligomer formation and progression of neurocognitive dysfunction. PLoS One 2009, 4:e6197

55. Bajetto A, Bonavia R, Barbero S, Florio T, Schettini G: Chemokines and their receptors in the central nervous system. Front Neuroendocrinol 2001, 22:147-184

56. Gowing G, Lalancette-Hebert M, Audet JN, Dequen F, Julien JP: Macrophage colony stimulating factor (M-CSF) exacerbates ALS disease in a mouse model through altered responses of microglia expressing mutant superoxide dismutase. Exp Neurol 2009, 220: 267-275

57. Grathwohl SA, Kalin RE, Bolmont T, Prokop S, Winkelmann G, Kaeser
SA, Odenthal J, Radde R, Eldh T, Gandy S, Aguzzi A, Staufenbiel M, Mathews PM, Wolburg H, Heppner FL, Jucker M: Formation and maintenance of Alzheimer's disease beta-amyloid plaques in the absence of microglia. Nat Neurosci 2009, 12:1361-1363

58. Manczak M, Mao P, Nakamura K, Bebbington C, Park B, Reddy PH: Neutralization of granulocyte macrophage colony-stimulating factor decreases amyloid beta 1-42 and suppresses microglial activity in a transgenic mouse model of Alzheimer's disease. Hum Mol Genet 2009, 18:3876-3893

59. El Khoury J, Toft M, Hickman SE, Means TK, Terada K, Geula C, Luster AD: Ccr2 deficiency impairs microglial accumulation and accelerates progression of Alzheimer-like disease. Nat Med 2007, 13:432-438

60. Bondolfi L, Calhoun M, Ermini F, Kuhn HG, Wiederhold KH, Walker L, Staufenbiel M, Jucker M: Amyloid-associated neuron loss and gliogenesis in the neocortex of amyloid precursor protein transgenic mice. J Neurosci 2002, 22:515-522

61. Fuhrmann M, Bittner T, Jung CK, Burgold S, Page RM, Mitteregger G, Haass C, LaFerla FM, Kretzschmar H, Herms J: Microglial Cx3cr1 knockout prevents neuron loss in a mouse model of Alzheimer's disease. Nat Neurosci 13:411-413

62. Lopes JP, Blurton-Jones M, Yamasaki TR, Agostinho P, LaFerla FM: Activation of cell cycle proteins in transgenic mice in response to neuronal loss but not amyloid-beta and tau pathology. J Alzheimers Dis 2009, 16:541-549 